\title{
People Skills and the Labor-Market Outcomes of Underrepresented Groups
}

Lex Borghans

Bas ter Weel

Bruce A. Weinberg 



\title{
People Skills and the Labor-Market Outcomes of Underrepresented Groups*
}

\author{
Lex Borghans \\ Department of Economics and ROA, Maastricht University \\ 1.borghans@ roa.unimaas.nl \\ Bas ter Weel \\ CPB Netherlands Bureau for Economic Policy Analysis \\ Department of Economics, Maastricht University \\ b.ter.weel@cpb.nl \\ Bruce A. Weinberg \\ Department of Economics, Ohio State University \\ weinberg.27@osu.edu
}

\begin{abstract}
This paper shows that people skills are important determinants of labor-market outcomes, including occupational choice and wages. Technological and organizational changes have increased the importance of people skills in the workplace. We particularly focus on how the increased importance of people skills has affected the labor-market outcomes of underrepresented groups assuming gender differences in interactions and that cultural differences (including prejudice) may impede cross-racial and ethnic interactions. Our estimates for Britain, Germany and the United States are consistent with such an explanation. Acceleration in the rate of increase in the importance of people skills between the late 1970s and early 1990s in the US can help explain why the genderwage gap closed and the black-white wage gap stagnated in these years relative to the preceding and following years.
\end{abstract}

Keywords: Interpersonal Interactions; Wage Level and Structure; Economics of Minorities and Races and Gender; Social Capital

JEL codes: $\mathrm{J} 16 ; \mathrm{J} 21 ; \mathrm{J} 24 ; \mathrm{J} 31$

\footnotetext{
* We wish to thank conference and seminar participants at Brown University, De Nederlandsche Bank, the 2004 EALE in Lisbon, IZA, LSE, Maastricht University, the NBER Summer Institute, Notre Dame University, Ohio State University, the 2004 SOLE in San Antonio, Yale, and the 2006 AEA Meetings. We are also grateful for comments from the three referees of this journal, David Autor, George Borjas, Charles Brown, Bertrand Candelon, William Dupor, Richard Freeman, Roland Fryer, Ed Glaeser, John Ham, Masanori Hashimoto, Larry Katz, Hajime Miyazaki, Franz Palm, James Peck, Bas Straathof, and Thomas Tenerelli. Vasilios Kosteas provided excellent research assistance. Ter Weel acknowledges financial support from the Netherlands Organization for Scientific Research and Weinberg acknowledges support from the National Science Foundation. We are grateful to Francis Green for access to the BSS data, to Alexandra Spitz-Oener for help with the BIBB/IAB data, to David Autor and Michael Handel for sharing the consistent series of occupation classifications for the United States, and for Donghoon Lee for sharing his matched CPS data. Part of this work was done while Borghans and Ter Weel were visiting the Department of Economics at Ohio State University and while Weinberg was visiting UNU-MERIT and ROA at Maastricht University. We are grateful for their hospitality and support.
} 


\section{Introduction}

In the United States the gender-wage gap shrank rapidly from the late 1970s to the early 1990s after holding steady for years, while the black-white wage gap closed more slowly during this period after shrinking for years. Both of these trends are shown in Figure 1, which is discussed in greater depth below. A variety of explanations have been provided for these patterns but there are no unified explanations and some of the explanations for one phenomenon deepen the puzzle for the other. ${ }^{1}$ This paper shows that trends in the importance of people skills provide a unified explanation for these patterns. While psychologists have pointed to gender differences in interpersonal styles and a long-standing literature discusses impediments to cross-racial interactions in the labor market, to the best of our knowledge, we are the first to link changes in the importance of people skills to the labor-market outcomes of underrepresented groups.

We conceptualize people skills as the ability to effectively interact with or handle interactions with people, ranging from communication with to caring for to motivating them. We argue that the diffusion of information and communication technologies and innovative work practices (as well as the shift in employment from manufacturing to services) generated an acceleration and then deceleration in the demand for "people people". And, while the importance of people skills (and noncognitive tasks more generally), has long been recognized in the popular literature and in psychology, ${ }^{2}$ aside from a few early contributions (Bowles and Gintis (1976); Mueser (1979)), their importance is only now being recognized in economics (e.g., Borghans, Duckworth, Heckman and ter Weel (2008) for a review of the evidence).

We provide a simple model of the role of people skills in the labor market. In our model, individuals vary in their stock of people skills and jobs differ in the importance of people tasks. People with more people skills have higher marginal products in jobs where people tasks are more important and are assigned to them. ${ }^{3}$ Using individual-level longitudinal data from the United States (supplemented by information from Britain), we show that people who were more sociable when they were young are more likely to be in jobs where people tasks are more important and that the

\footnotetext{
${ }^{1}$ For instance Blau and Kahn ((1997)) show that the increase in skill prices proposed by Juhn, Murphy and Pierce ((1991)) can explain the slowing progress of blacks but that it works against the closing of the gender gap. Bacolod and Blum (2010) present evidence that increased demand for social skills might be related to the narrowing of the gender gap, but do not address changes in racial gaps.

2 Work in psychology includes, Gardner ((1983)), Sternberg ((1984)), and Goleman ((1996)). The massive market for material on How to Win Friends and Influence People, as Dale Carnegie's ((Carnegie 1936)) classic book is titled, indicates that people tasks are widely believed to be important. Carnegie's work has sold over 15 million copies and, over 70 years after it was first published, is ranked in the top 100 among all books on Amazon.com.

${ }^{3}$ Borghans, ter Weel, and Weinberg (2008); and Krueger and Schkade (2008) also study how people skills affect the assignment of people to jobs.
} 
returns to their people skills have tracked the gender and race gaps. These results demonstrate the widespread influence of people skills, corroborate the trends in the people skills premium, and validate our measures of people tasks.

After this general analysis of people skills, we apply our model to understand changes in the labor-market outcomes of underrepresented groups. This analysis rests on two foundations. The first element is a difference across groups in the performance of interpersonal tasks. Psychologists have argued that women place more weight on the effects of their actions on others (Gilligan 2001) and women report being better in performing people tasks. This difference is confirmed by neurological evidence, with a larger share of women's brains being devoted to self-knowledge and empathy. ${ }^{4}$ It is also likely that racial, ethnic, linguistic, and cultural differences impede the performance of people tasks, because customers or co-workers from the majority group prefer to interact with other members of the majority group because of cultural differences and/or prejudice (Becker (1971), Holzer and Ihlanfeldt (1998) and Lazear (1999)).

The second foundation is an acceleration and then deceleration in the relative importance of interpersonal tasks in the labor market, which tracks the gender-wage gap and is a mirror image of the racial wage gap. As shown in Figure 2, whose construction is detailed below, the importance of people tasks increased particularly rapidly between the late 1970s and the early 1990s and, as shown below, these dynamics are unique to people tasks.

Although it is not critical for our analysis of underrepresented groups, we speculate that the primary driving force in these shifts is a reduction in the real price of computing power, which endogenously and non-monotonically shifted the set of tasks that can efficiently be computerized, first increasing the relative importance of people skills by automating other aspects of jobs but, more recently, improving the relative ability of computers to perform interactive tasks (e.g., Bresnahan 1999; Autor, Levy and Murnane 2003; Borghans and ter Weel 2004; Bloom, Garicano, Sadun and Van Reenen 2009). ${ }^{5}$

To understand this monotonicity, consider that neuropsychologists (see Goldstein et al. 2001) have documented that a large share of the brain is devoted to interactive tasks directly and

\footnotetext{
${ }^{4}$ Men's brains tend to be larger than women's brains, largely because men's bodies are larger than women's bodies, so the most relevant comparison is of the share of brains devoted to specific tasks.

${ }^{5}$ Like, Bloom Garicano, Sadun and Van Reenen (2009), we assume that the nature of information and communication technologies is not uniform. They assume that information technology and communication technology have different effects on the organization of work and the division of labor. Information technology is associated with more worker autonomy and generalization, whereas communication technology reduces worker autonomy and induces more specialization. We account for changes in the nature of information and communication technologies over time. See also Borghans and ter Weel (2006) and Prasad (2009) for similar models.
} 
indirectly. ${ }^{6}$ By contrast, only a relatively small part of the brain (roughly four percent) is devoted to general problem solving. A new technology would be unlikely to have this specialization. As Entwistle (2003) notes, "Communication between humans and computers is a prerequisite to employing computers as an effective human tool (p. 127)", but "Very early human-computer communication devices (...) were extremely difficult for humans to learn and understand (p. 128).” So, it is natural that the first applications of computers were to non-people tasks such as large calculations and bookkeeping (e.g., Bresnahan and Greenstein 1996). ${ }^{7}$ By automating non-people tasks, computers initially increased the relative demand for people to perform people tasks. ${ }^{8}$

Through dramatic improvements in processing speed and memory, computers have become relatively better in interactive tasks. The introduction of the world wide web in the early 1990s is an important step in the development of computers from calculators to interactive machines, in many cases allowing "customers" to perform tasks online that would have otherwise required interactions. Graphical user interfaces also illustrate how the decline in the price of computing power has improved human-computer interactions. The progress with and remaining limitations of computers in people tasks are well illustrated by face and voice recognition. ${ }^{9}$ Thus, we argue that while computers initially increased the importance of interpersonal tasks, this relationship weakened or disappeared as computers increasingly performed people tasks.

To investigate the effect of people skills on the labor-market outcomes of underrepresented groups, we show that in both cross-sectional and panel data, the relative employment of women is higher in occupations in which people tasks are more important in Britain, Germany and the United

\footnotetext{
${ }^{6}$ Vision takes up the largest brain volume, with facial recognition occupying a considerable part of this component. The second largest specialization is language (even when hearing is classified separately). The motor system is the third largest part. Self-awareness and empathy also occupy smaller, but considerable amounts of brain volume.

${ }^{7}$ When earlier general-purpose technologies such as mechanization and electrification are compared to computers, it is clear that these earlier technologies were better in physical or motor tasks compared to computers, but these technologies were also (initially) weak in interactive tasks. Over time, improvements in mechanization ultimately lead to breakthroughs in travel while electricity ultimately leads to breakthroughs in communication (telephones, radio, film, and television).

${ }^{8}$ Of course, computers also increased the demand for a small set of highly-technical occupations focused on programming and developing computers, but as our data show, the primary effect was to increase the relative demand in interactive tasks.

9 Voice recognition has improved tremendously, with software achieving 99 percent accuracy under "optimal" conditions (Dayal, 2006) and up to 80 percent accuracy under more typical circumstances (Entwistle, 2003). Nevertheless, major hurdles to automated speech recognition remain. "Computer scientists have two major hurdles to overcome before automated speech recognition (ASR) technology can become a universal human-computer interface: recognition of continuous speech and speaker independence (Entwistle 2003, p. 130)." Williams (2007) writes, "Face recognition has been getting pretty good at full frontal faces and 20 degrees off, but as soon as you go towards profile, there've been problems." Bonsor and Johnson (2001) write, "Other conditions where face recognition does not work well include poor lighting, sunglasses, long hair, or other objects partially covering the subject's face, and low resolution images."
} 
States. The reverse is true for racial, ethnic, cultural, and linguistic minorities in the United States. ${ }^{10}$ We combine these elements, showing that trends in the demand for people skills implied by trends in the employment and wages of underrepresented groups closely mirror trends in the importance of people skills in the labor market.

\section{Background}

There are large literatures on trends in the gender and race gaps and on the labor-market participation of women and blacks (Altonji and Blank 1999 provide a survey). We begin with a discussion of the literature on trends in women's labor markets. A large literature shows that the gender-wage gap was relatively stable over much of the $20^{\text {th }}$ century (Goldin 1990 provides a comprehensive analysis). Starting in the late 1970s, the gender-wage gap began to close. Weinberg (2000) and Welch (2000) attribute much of this convergence to new technologies, which have deemphasized the (physical) disadvantages women had in a many jobs. Black and Brainerd (2004) argue that globalization has increased competition through trade, contributing to a closing of the gender-wage gap in concentrated relative to competitive industries. Bacolod and Blum (2010) show that increased demand for social skills contributed to the narrowing of the gender-wage gap. From the mid-1990s on however, women's wages are again flat, a development so far unexplained. Blau and Kahn (2004) explore a variety of factors for this flattening. Their analysis is as much negative (ruling out possible explanations) as positive, but they conclude that less favorable supply and demand shifts are among the likely explanations for the slowing convergence of the gender-wage gap.

A longstanding literature has studied gender differences in occupation mix (Blau, Ferber, and Winkler 2006 provide trends and discuss the literature). We contribute to this literature by exploring the extent to which people skills contribute to these differences. Others have sought to explain the gender-wage gap using occupational segregation (e.g., Bayard, Hellerstein, Neumark and Troske 2003). Although less closely connected to the present piece, the literature emphasizes the striking increase in labor attachment and skill investments among highly-skilled women (Goldin 2002; 2004a; 2004b; Goldin and Katz 2002). However, none of this work is able to explain the break in the gender-wage gap trend since the mid-1990s.

\footnotetext{
${ }^{10}$ We include results for Hispanics, but only as supplements to our results on the gender and racial wage. The wages of Hispanic workers decline markedly starting in the late 1970s, while their employment increases. Borjas (1982, 1995), Trejo (1997) and Borjas and Katz (2005) find that much of the gap in wages between Hispanics and non-Hispanics is explained by differences in education.
} 
Mulligan and Rubinstein $(2004 ; 2008)$ offer an alternative view on the evolution of the gender-wage gap. They argue that within-gender wage inequality has changed the composition of working women and argue that estimates that fail to account for changes in selection into employment overstate the closing of the gender-wage gap. Our estimates indicate a much smaller role for changes in selection and their estimates cannot be reconciled with trends in the importance of people tasks or movements in the racial-wage gap.

The racial-wage gap closed through the mid-1970s, which is often attributed to the Civil Rights Act of 1964 (See Smith and Welch 1989; Jaynes 1990; Heckman and Donohue 1991 for overviews of the labor-market position of blacks in the United States). ${ }^{11}$ Juhn, Murphy and Pierce (1991) and Smith (1993) attribute the slowdown in the closing of the racial-wage gap to slowing education gains, the sharp rise in returns to education in favor of white, prime-aged workers, and falling wages at the bottom end of the labor market which hurt low-educated black men severely. ${ }^{12}$ Bound and Freeman (1992) suggest that increases in the racial-wage gap are due to factors that are specific to education and geographic groups, not to the overall increase in wage inequality since the early 1980s. Among the most prominent explanations is the decreased emphasis on affirmative action during the Reagan administration, the decline of inner cities, the shift from manufacturing to services, the decline in union density, and the fall in real minimum wages, which hit young black workers hardest. Cutler and Glaeser (1997) add to this that the increased segregation of blacks worsens their economic and schooling performance, particularly if they live in central cities.

There are a number of papers that have studied selection bias in estimating black-white wage gaps. Using U.S. Census data, Chandra (2000) reports that labor-market participation among primeaged black men was considerably lower than the labor-market participation of white men in the period 1940-1990. Neal (2004) measures the black-white wage gap among women using a variety of U.S. data sources and finds that differences in participation between black women (often single mothers) and white women (often receiving support from a high-earning spouse) have led to a

\footnotetext{
${ }^{11}$ For example, Freeman (1973), Smith and Welch (1977; 1984), Brown (1984), Card and Krueger (1993), and Collins (2001) address the timing of the improvements in black workers' relative earnings. Using a variety of research strategies and data sources, they all find evidence consistent with a break in labor-market variables, such as relative employment and wages, in favor of blacks. The improvement in relative school quality in segregated states in the first half of the $20^{\text {th }}$ century is also seen as a source of falling racial-wage gaps since the 1960s. For example, Donohue, Heckman and Todd (2002) address the racial-wage gap in the period 1910-1960 and find considerable convergence in wages for cohorts born since the late 1930s, which they attribute to improvements in school quality in the South. Card and Krueger's (1992) findings are consistent with improvements in the relative quality of black schools in the first half of the $20^{\text {th }}$ century. Their estimates suggest that improved quality of schooling is able to explain about 20 percent of the narrowing of the racial-wage gap in the period 1960-1980.

12 See also Juhn (1992). Neal and Johnson (1996) suggest that racial discrepancies in basic skills due to differences in education and family background are also important factors in explaining the slowdown in the convergence of the racialwage gap. Card and Lemieux (1994) find mixed results for the returns to skill.
} 
downward bias in the measured black-white wage gap. Chandra (2003) studies the efficacy of the Civil Rights Act and the development of the racial-wage gap in the period thereafter (see also Heckman, Lyons and Todd (2000)). His estimates suggest that selection bias plays a considerable role in understanding racial-wage gaps.

Our work is also related to the literature developing task-based models in which the assignment of workers is determined by technological change. Acemoglu and Autor (2011) summarize this literature and present a framework for analyzing recent trends in employment and wages. Other task models to understand the effects of technological change on labor-market outcomes have been developed in Autor, Levy and Murnane (2003), Borghans and ter Weel (2004), Autor, Katz and Kearney (2006) and Borghans, ter Weel and Weinberg (2008).

Finally, our work falls into the emerging literature on "soft skills," which includes evidence of premia for beauty (Hamermesh and Biddle 1994), Machiavellianism (Turner and Martinez 1977), personality (Osborne 1999), self-esteem (Goldsmith, Veum and Darity 1997), leadership (Kuhn and Weinberger 2005) and to height among youths (Persico, Postlewaite, and Silverman 2004). In a companion paper (Borghans, ter Weel and Weinberg 2008) we elaborate more on the types of interpersonal skills important for different jobs. Based on British and German data we estimate an assignment model and find that some jobs require more decisiveness and others a more caring interpersonal style. This body of work supports our result of positive labor-market premia for people skills, but each only captures one dimension of interpersonal styles. A few recent papers in this literature address underrepresented groups. Fortin (2008) analyzes the impact of noncognitive traits on the gender-wage gap by assessing whether differences in outcomes are associated with gender roles using the NLS72 and NELS88. Black and Spitz-Oener (2010) argue that a technology-driven shift from routine tasks to non-routine analytic and interpersonal tasks among women can help explain the closing of the gender wage gap. Urzua (2008) estimates a model of schooling and labormarket outcomes with unobserved cognitive and noncognitive abilities in order to explain the racialwage gap. His analysis integrates schooling decisions and labor-market outcomes to study whether the observed racial gaps in labor-market outcomes can be interpreted as a manifestation of racial differentials in unobserved abilities. Lastly, Weinberger (2009) shows that the importance of leadership skills increased over the past three decades, with a declining rate of increase in more recent years, results that are consistent with the trends in the importance of people tasks and the premium to people skills we find here. Borghans, Duckworth, Heckman and ter Weel (2008) summarize this literature. 


\section{Framework}

This section develops a simple model of people skills that serves as a framework for a wide range of analyses of the effect of people skills on labor-market outcomes. Our empirical work shows that people skills are important determinants of individual labor-market outcomes, affecting the occupations that people enter and their earnings. We augment standard wage regressions by including measures of youth sociability to get at the labor-market premium associated with possessing people skills and show that the premium associated with possessing people skills has changed over time. We analyze the supply and demand for people skills. Key components of this approach are to identify trends in the importance of people tasks in the labor market and the skill endowments of race-gender groups, both of which are unobserved. Given these different analyses, we structure our model to be convenient for both individual-level and market-level analyses.

We assume that there are two types of jobs - people jobs, denoted by $P$, and non-people jobs, denoted by $N$. Output is a (constant elasticity of substitution) function of the amount of effective labor in the $P$-job and the $N$-job. For much of our analysis, we categorize the workforce based on two demographic characteristics - race (black and non-black) and gender. In the model, the four groups (black women, black men, non-black women, and non-black men) differ in terms of the distribution of people skills. Differences in these distributions reflect the attitudes of groups toward each other as well as differences in innate ability to perform people tasks. Thus, while there are reasons to believe that women deal better with people than men, we emphasize that we do not believe that there are racial or ethnic differences in the ability to perform people tasks. Rather, racial, ethnic, linguistic, and cultural differences interfere with the performance of people tasks, either because cross-group interactions are difficult or because of prejudice on the part of customers and co-workers (see e.g., Lazear (1999) for a similar point of view on culture and language acquisition). To simplify the analysis, these differences are modeled in terms of the share of people "with people skills."

For simplicity, we assume that peoples' endowments of people skills are binary, with $\pi_{P \mid x}$ denoting the share of people with characteristics $x$ that have people skills. This notation is intentionally flexible. In our individual-level analyses " $x$ " refers to the characteristics of a given person. We also partition the population based on race and gender, in which case $x \in\{B W, B M, N W, N M\}$ refers to a specific gender-race group. Here, if more women than men are good with interpersonal interactions, then $\pi_{P \mid B W}>\pi_{P \mid B M}$ and $\pi_{P \mid N W}>\pi_{P \mid N M}$. If inter-racial 
interactions are difficult and non-blacks constitute a favored majority group, then $\pi_{P \mid N W}>\pi_{P \mid B W}$ and $\pi_{P \mid N M}>\pi_{P \mid B M}$.

We assume that only people "with people skills" can work in people jobs and vice-versa for non-people jobs. The aggregate supplies of efficiency labor to $P$-jobs and $N$-jobs are $L_{P}=\sum_{x} n_{x} \pi_{P \mid x}$ and $L_{N}=\sum_{x} n_{x}\left(1-\pi_{P \mid x}\right)$, where $n_{x}$ gives the number of people with characteristics $x$. In this model, the supply of people and non-people workers is inelastic. (With a continuous distribution of people skills, an increase in the wage in the people sector increases the supply of workers in efficiency units to people jobs, even when the composition of the workforce is fixed.)

Final output is $y=\left(\delta L_{P}{ }^{-\rho}+(1-\delta) L_{N}{ }^{-\rho}\right)^{-\frac{1}{\rho}}$. In equilibrium, wages equal the marginal product of labor, so wages in people jobs, $w_{P}$, and non-people jobs, $w_{N}$, satisfy

$$
\ln \left(\frac{w_{P}}{w_{N}}\right)=\ln \left(\frac{\delta}{1-\delta}\right)-\frac{1}{1+\rho} \ln \left(\frac{L_{P}}{L_{N}}\right)
$$

\section{Implications for Job Assignment}

Our empirical analysis about job assignment begins by showing that measures of youth sociability are related to the importance of people skills in an individual's adult job. Let $\pi_{P \mid \text { Sociabiliy }_{i}}$ denote the probability that person $i$ has people skills as a function of his or her sociability as a youth (other controls, including gender and race can be included). Youth sociability can be interpreted as being associated with a higher probability that a person has people skills and hence is employed in a people job.

\section{Implications for Individual Earnings}

We provide individual-level evidence that the premium to people skills has increased over time. In the simplest model, the $\log$ wage of person $i$ at time $t$ is

$$
\ln \left(w_{t i}\right)=\ln \left(w_{N}\right)_{t}+\ln \left(w_{P} / w_{N}\right)_{t} \pi_{P \mid \text { Sociabilit }_{i}}+\varepsilon_{t i}
$$

Thus, the coefficient on sociability gives the premium to people skills at time $t$ interacted with the probability that someone has people skills. Changes in the coefficient on sociability capture changes 
in the premium to people skills. ${ }^{13}$

\section{Implications for Groups}

To study changes in the supply and demand for people skills on the relative wages of racegender groups, we require information on the share of each group with people skills and the importance of people tasks in the labor market. The share of people with characteristics $x$ among people with people skills is $\pi_{x \mid P}=\frac{\pi_{P \mid x} n_{x}}{\sum_{\tilde{x}} \pi_{P \mid \tilde{x}} n_{\tilde{x}}}$. As above, $n_{x}$ gives the number of people with characteristics $x$. The share of people with characteristics $x$ among people who do not have people skills is $\pi_{x \mid N}=\frac{\left(1-\pi_{P \mid x}\right) n_{x}}{\sum_{\tilde{x}}\left(1-\pi_{P \mid \tilde{x}}\right) n_{\tilde{x}}}$. If people with (and without) people skills with each set of characteristics are assigned to jobs that do (not) require people skills in proportion to their share in the economy (i.e., the amount of discrimination in the people and non-people job does not vary across sectors) then the share of jobs in sector $s$ that will be filled by people with characteristics $x$ is

$$
\pi_{x \mid s}=\pi_{P \mid s} \pi_{x \mid P}+\left(1-\pi_{P \mid s}\right) \pi_{x \mid N}=\pi_{x \mid N}+\pi_{P \mid s}\left(\pi_{x \mid P}-\pi_{x \mid N}\right) \text { for } x \in\{B W, B M, N W, N M\},
$$

where $\pi_{P \mid s}$ gives the share of jobs in sector $s$ that are people jobs. Thus, (modulo a constant term) the employment share of the four groups among the workers in sector $s$ is proportional to the importance of people skills in sector $s$.

To estimate the share of the people in each group who have people skills, we use the relationship between the employment shares of the four (gender-race) groups and the importance of people skills, which we take as our measure of $\pi_{P \mid s}$, across occupations. As people jobs become more important in sector $s$, the change in the employment share of a group in sector $s$ is

$$
\frac{d \pi_{x \mid s}}{d \pi_{P \mid s}}=\pi_{x \mid P}-\pi_{x \mid N} \text { for } x \in\{B W, B M, N W, N M\}
$$

Estimating $\frac{d \pi_{x \mid s}}{d \pi_{P \mid s}}$ is straightforward. It is the coefficient on the share of jobs in sector $s$ that are people jobs in a regression of the employment share of the four groups in a sector on the importance of people tasks in that sector. With estimates for $d \pi_{x \mid s} / d \pi_{P \mid s}$ (and other estimable information), it is

\footnotetext{
${ }^{13}$ When we proceed to estimation, we will control for other factors that affect wages and impose a linear trend with a break on the importance of people skills.
} 
possible to estimate the share of workers in each group with people skills, the $\pi_{P \mid x}$ for $x \in\{B W, B M, N W, N M\}$.

\section{Empirical Implementation}

This section provides the most salient details about the several data sources we use to analyze trends in labor-market outcomes of underrepresented groups. In addition, it presents the way in which we construct measures of people skills. The Data Appendix provides more detailed information and descriptive statistics.

\section{Data Sources}

Our analysis requires measures of the importance of tasks performed in occupations and how these tasks change over time. Our main source for data on the United States is the Fourth (1977) Edition and the Revised Fourth (1991) Edition of the U.S. Department of Labor's Dictionary of Occupational Titles (DOT). ${ }^{14}$ Examiners from the U.S. Department of Labor used a unified framework to assess 12,000 occupations along 44 objective and subjective dimensions. ${ }^{15}$

We follow the strategy of Autor, Levy and Murnane (2003) and append DOT occupation characteristics to the Current Population Survey (CPS) March files to get a picture of the trends over a longer period, in this case 1971-2002. Our main source of information is drawn from the Fourth (1977) Edition of the DOT because it contains more detailed information on job tasks than the Revised Fourth (1991) edition. ${ }^{16}$

We also append the DOT to estimates of the demographic composition of occupations estimated from the 1980 and 1990 U.S. Censuses to investigate the effect of people skills on the employment shares of underrepresented groups. Details about the construction of the variables are in the next section. Details on the merging of databases can be found in the Data Appendix, particularly in Sections A1 and A2.

\footnotetext{
${ }^{14}$ The DOT has been updated four times since its first edition in 1939 (1949, 1965, 1977, and 1991). However, the structure did not change significantly during these revisions. The most recent revision has led to the Occupational Information Network (O*NET) a more up-to-date source of information, but one that is completely redesigned.

${ }^{15}$ See the Handbook for Analyzing Jobs (U.S. Department of Labor 1972). Other researchers have been using the DOT to analyze changing job requirements (Rumberger 1981), to address and compare different ways to measure skill requirements (Spenner 1990), and to estimate how the importance of routine and non-routine job tasks are affected by computerization and how they affect labor demand (Autor, Levy and Murnane 2003).

${ }^{16}$ Autor, Levy and Murnane (2003) and Autor and Handel (2009) provide a discussion of the limits of using DOT measures.
} 
To complement these analyses we draw on a number of other databases. First, for our U.S. analysis we use the National Longitudinal Survey of Youth of 1979 (NLSY79), which contains information on youth sociability. We investigate whether people who are more sociable when young are employed in occupations where people tasks are more important as adults using the DOT task measures. For this analysis, we match each NLSY79 respondent to the job tasks for his or her threedigit occupation in each year constructed from the DOT. We also use the NLSY79 to study trends in the premium associated with youth sociability (see Table A2 in the Data Appendix for definitions and variable construction).

If technological change is affecting the importance of people skills, we would expect the effects to be pervasive (as in Berman, Bound, and Machin 1998). We complement the analysis of U.S. data with estimates using British and German data. We use the First (1997), Second (2001), and Third (2006) British Skills Surveys (BSS) of the ESRC Centre on Skills, Knowledge and Organisational Performance (SKOPE) at Oxford University to obtain information about job tasks in Britain. The BSS assesses not just the presence, but the importance of 36 job activities and key skills, including people tasks for all jobs. ${ }^{17}$ The BSS also contains measures of computer use, which we use to estimate the determinants of the importance of people skills.

We use the 1970 British Cohort Study (BCS), which follows all people born in the week of April 5, 1970, to relate measures of sociability and personality at age 16 to labor-market outcomes at age 30. To compare current job tasks with sociability at younger ages, we append information on the tasks performed in three-digit occupations estimated in the BSS to the BCS. Table A2 in the Data Appendix shows the definitions of the sociability variables in the BCS.

Finally, we use data from Germany collected by the Bundesinstitut für Berufsbildung (BIBB) in Berlin and Institut für Arbeitsmarkt- und Berufsforschung der Bundesanstalt für Arbeit (IAB) in Nürnberg. The BIBB/IAB database contains worker surveys in 1979, 1985, 1991 and 1998, with information about a worker's job tasks. An advantage of the task information in the BIBB/IAB relative to the DOT and BSS is that it contains four waves of data on job tasks over a relatively long period of time. ${ }^{18}$ The BIBB/IAB also contains data on computer use, which we use to estimate how technological change is related to the importance of people tasks.

\footnotetext{
${ }^{17}$ Ashton, Davies, Felstead and Green (1998) provide a detailed overview of the design and present basic analyses of the BSS. Felstead, Gallie and Green (2002) and Felstead, Gallie, Green and Zhou (2007) present overviews of the second and third BSS.

${ }^{18}$ See Spitz-Oener (2006) and Gathmann and Schönberg (2010) for detailed descriptions and different uses of these data.
} 
People Tasks

To measure the importance of people tasks in the DOT, we use five variables. Three are binary indicators of the presence or absence of a given temperament that measure adaptability requirements of workers in specific job-worker situations. These are (i) adaptability to situations involving the interpretation of feelings, ideas or facts in terms of personal viewpoint, (ii) adaptability to influencing people in their opinions, attitudes or judgments about ideas or things, and (iii) adaptability to dealing with people beyond giving and receiving instructions. We also include two variables from the DOT's interest factors to signify interests, tastes and preferences for certain kinds of activities that are entailed in job performance. These are (i) a preference for activities involving business contact with people, and (ii) a preference for working for the presumed good of people. The interests take on three values, $-1,0$, or 1 . We first aggregate the DOT occupation classification to a consistent set of Census occupations (as described in Appendix A.1). We then normalize these five variables by their standard deviations and use their sum. ${ }^{19}$

For the BSS we measure the importance of people tasks by aggregating variables measuring the importance of dealing with people; working with a team of people; instructing, training or teaching people; making speeches or presentations; persuading or influencing others; selling a product; counseling, advising or caring for customers or clients; and listening carefully to colleagues. We selected three variables that are comparable to the DOT's general educational development (GED): reading, writing, and math. For each occupation, we estimate the importance of planning job activities, knowledge about the organization and products, problem solving, noticing problems and (procedural) faults, and physical skills and work. The BSS characterizes job requirements on a five-point scale, giving a more nuanced picture than the binary information in the DOT. $^{20}$

The BIBB/IAB contains binary indicators of job tasks. To obtain a consistent series over time, we aggregated this information to the level of two-digit occupations, in a way that is similar to Spitz-Oener (2006). In the BIBB/IAB, we measure the importance of people tasks in an occupation

\footnotetext{
${ }^{19}$ Formally, let $v_{j o}$ denote the value of variable $j \in\{1, \ldots, 5\}$ in occupation $o$ and $\sigma_{j}$ denote its standard deviation across occupations, our measure of the importance of people skills in occupation $o$ is $\sum_{j} v_{j o} / \sigma_{j}$. For the most part, we use the 1977 DOT to measure $v_{j o}$. Autor, Levy and Murnane (2003) use percentile rankings of the DOT scores rather than raw DOT scores. Results are similar when we do so.

${ }^{20}$ Because respondents to the BSS rate their own occupation, the implicit scales they use may differ. There is evidence that self-assessment provides satisfactory results, however. Spenner (1990) presents evidence that there is a high correlation between self-reported job requirements and measures obtained from controlled experiments and expert evaluation, such as the DOT.
} 
using the fraction of six different people tasks performed by the average worker in that occupation. Our six people tasks are teaching or training; negotiating, lobbying, coordinating and organizing; serving others; helping others; selling, buying, advising customers and advertising; and entertaining or presenting. Table A1 in the Data Appendix offers the definitions of people tasks in our data sources.

\section{Trends and Explanations}

We start our empirical analysis by documenting and exploring trends in the gender and racial-wage gaps and changes in the importance of people skills in the United States.

\section{Gender and Race Gaps}

This section discusses trends in the labor-market outcomes of women and blacks in the United States. Figure 1 (above) shows the evolution of the male-female (left) and the black-nonblack (right) wage gaps in the United States from 1968 to 2002, using data from the March Current Population Surveys (CPS). The estimates are based on weekly wages and are adjusted for observable characteristics, incarceration, and trends in employment (the procedures are described in Appendix A.2). The series for women and men are broken down by race and the series for blacks and non-blacks are broken down by gender.

The figure shows that women's wages show little growth until the 1970s, at which point they begin rising rapidly until the mid-1990s, when they started growing less rapidly. This pattern is particularly pronounced among blacks. The overall gender-gap follows that for white women quite closely. By contrast, the racial-wage gap closes rapidly until the mid-1970s. It then expands until the late 1980 s or early 1990 s before closing again. ${ }^{21}$

Figure 3 shows the employment shares by gender and race in the United States from 1964 to 2003. Women's share of employment increased steadily over this period, with a deceleration among non-black women in the 1990s. It is noteworthy, that even in the years where women's employment was increased most rapidly, the gender-wage gap was closing. The employment of blacks, especially black women, increased over the period, with some acceleration in the most recent years. Given the strong historic labor-force attachment of black women, their employment exceeds that of black men since the early 1990s.

\footnotetext{
${ }^{21}$ The second period of convergence emerges because we impute faster wage growth for blacks than whites among people working in one, but not both years of the CPS since the mid-1980s.
} 


\section{The Importance of People Tasks}

To provide some indication of types of jobs in which people tasks are important, Table A3 lists the 25 largest three-digit occupations in the United States and Table A4 lists the 10 largest twodigit occupations in Germany sorted by the importance of people tasks. Despite the differences between the countries and the differences in the classifications, in both countries people tasks are particularly important for nurses, teachers, sales workers, and secretaries. People tasks are relatively unimportant for machine operators and truck drivers. Overall, there are high and low-skilled occupations at both ends of the distribution of people tasks. Table A5 lists the 10 occupations with the largest increases and decreases in the importance of people tasks in Germany between 1979 and 1991 (we use German data because they contain a more complete and longer time series than data from the United States). Most, but not all, of the occupations with increases are the ones in which people tasks were originally important. The ones with declines are those in which people tasks were not very important originally. Thus, there is an accentuation of the variations in the importance of people skills.

Figure 2 (above) documents the increase in the importance of people tasks in the United States from 1971 to 2002. The estimates are averages of tasks in three-digit occupations from the 1977 Dictionary of Occupational Titles (DOT), which are weighted by the fraction of the workforce in each occupation (Appendix A.1 provides details about the definition of people tasks). Thus, this figure gives the trend in the importance of people tasks arising from shifts between three-digit occupations. The graph shows that the trend toward increased importance of people tasks accelerated in the late 1970s or early 1980s and decelerated in the early 1990s.

Insofar as much of the shift in the importance of people tasks occurs within occupation categories, this figure understates the full increase in the importance of people tasks. ${ }^{22}$ While caution is required in inferring the exact timing or magnitude of the increase in the importance of people skills, the acceleration in the late 1970s or early 1980s and deceleration in the early 1990s bears a striking resemblance to trends in the wages of women and blacks, a link we investigate further below. Figure 4 presents trends in the other tasks. It is noteworthy that these series for the importance of other tasks do not show the same acceleration and deceleration, implicating people

\footnotetext{
${ }^{22}$ We compare the size of the within and between-occupation changes using data from Germany. In those data, we estimate that 95 percent of the increase in the importance of people tasks arises within occupations. We estimated crossregion regressions of within-occupation changes in people tasks on between occupation changes. Taking these estimates as indications of the relationship between within and between-occupation changes, the total increase in the importance of people tasks is likely to be at least 3.6 times the between-change and potentially much larger.
} 
tasks as the most likely task for explaining trends in the gender and racial-wage gaps.

\section{Technological Change and the Importance of People Tasks}

This section seeks to understand the driving forces behind the acceleration and deceleration in the relative importance of people tasks. As indicated, we hypothesize that computers initially substituted for routine cognitive tasks, increasing the importance of difficult-to-computerize people skills. ${ }^{23}$ With the decline in the real price of computing power, computers have been increasingly used to automate people tasks weakening the relationship between computerization and the importance of people tasks over time. ${ }^{24}$

Table 1 provides some evidence on this hypothesis, reporting estimates of the change in the importance of people tasks on changes in computerization across occupations in the United Kingdom and Germany. ${ }^{25}$ Although the estimates are not comparable across countries, they are comparable within each country.

In Britain, the importance of people skills and computer use are all estimated at the threedigit occupation level from the BSS. The estimates show that in the late 1990s, increases in computerization are associated with increases in the importance of people tasks. While the relationship still exists in the early 2000s, the coefficient has fallen substantially.

For Germany, we relate the importance of people tasks to computer use in two-digit occupations in the BIBB/IAB. These data, which cover a substantially longer time period, show a similar pattern, with a strong relationship between increases in computerization and increases in the importance of people tasks in the early 1980s, declining somewhat in the late 1980s, and disappearing during the 1990s.

Overall, our estimates suggest that computerization is initially associated with increases in the importance of people tasks, but that the relationship has weakened over time (albeit at different rates given the different measures in the different countries). These patterns are consistent with

\footnotetext{
${ }^{23}$ Firms have also adjusted their organizational structures to make the most of computer technology, emphasizing teams and quality circles as well as skill (Caroli and Van Reenen (2001), Bresnahan, Brynjolfsson and Hitt (2002), Ichniowski and Shaw (2003) and Bloom, Garicano, Sadun and Van Reenen (2009)). These changes require workers to communicate and work with others more effectively.

${ }^{24}$ Of course, computers also increased employment in occupations like programming where people skills are less important. Interestingly programmers are the occupation with the fourth largest increase in the importance of people skills. The estimates below indicate that computers were generally associated with an increased importance of people skills within occupations.

${ }^{25}$ The 1991 update of the DOT was limited, effectively preventing a similar analysis for the United States. See also Autor, Levy and Murnane (2003) for a discussion of these limitations. Recently, effort has been put in linking the DOT task measures to measures of its successor (O*Net) (e.g., Acemoglu and Autor 2011, Autor and Handel 2009 and Autor and Dorn 2009).
} 
computers (endogenously) becoming relatively more effective in automating people tasks over time as the price of computing power has declined.

\section{Individual-Level Evidence on People Skills and Labor-Market Outcomes}

We continue the empirical analysis by presenting individual-level evidence on the link between people skills and labor-market outcomes.

\section{Youth Sociability and Adult Occupations}

We begin by relating people's sociability as youths to the tasks that are important in their adult occupations. Following the model, we interpret youth sociability as being associated with a higher probability that someone has people skills.

These results play two roles. A positive relationship between sociability and the importance of people tasks in people's occupations will validate our measures of the importance of people tasks and sociability (as a measure of the ability to perform people tasks). They also show that variations in people skills affect labor-market outcomes. How sociability as a youth is related to the importance of other tasks will depend on whether people skills complement other skills and whether people with good people skills are also endowed with more of other skills. If they are, people with stronger people skills will tend to be in jobs where other tasks are more important. We present estimates for the United States and Britain.

The first set of estimates comes from using the National Longitudinal Survey of Youth of 1979 (NLSY79). The 1984 wave of the NLSY79 contains data on the number of social clubs respondents participated in during high school. The 1985 survey contains data on contemporaneous sociability (when the respondents were 20-28 years old) and sociability at age six. Exploiting the panel aspect of the data, we regress the 1977 DOT scores for the respondents' occupations in all years on their responses to these questions (see Appendix A.2 for details). Our models include random effects for respondents and dummy variables for calendar years.

Table 2 reports the estimates. The first row shows a large positive relationship between the three measures of the respondents' sociability and the importance of people tasks in their adult occupations. The later rows report the relationship between the sociability variables and the importance of other skills. These models show that people who were more sociable when young are more likely to be in occupations where cognitive tasks are more important. The figures in brackets give the portion of a standard deviation in the task variables that can be explained by a one standard 
deviation change in sociability. The relationship between sociability (especially self-reported sociability) and the other tasks is much smaller than the relationship between sociability and people tasks, suggesting that sociability is particularly important in occupations where people tasks are important.

Next, we perform a similar analysis for Britain using the BCS and BSS. The age 16 round of the BCS conducted in 1986 includes a variety of behavioral measures of sociability, including the frequency with which the respondents spent time with friends during the school year and during holidays; the frequency with which time is spent with friends during leisure time (as opposed to nonsocial leisure activity); and number of friends. The survey also asks the extent to which respondents describe themselves as outgoing. To obtain measures of the importance of tasks on respondents' adult jobs, we assigned to each three-digit occupation the mean of the importance of the tasks for that three-digit occupation calculated from the 2001 BSS (see Appendix A.4 for details).

The first row of Table 3 shows that all of the indicators of social behavior are positively related to the importance of people tasks. The remaining rows report the relationship between the youth sociability measures and the importance of other tasks. With the exception of planning activities, which have an interactive component, there are no systematic relationships.

The finding that youth sociability is strongly related to the importance of people tasks in peoples' subsequent occupations provides validation for our measures of the importance of people tasks. It also shows that the importance of people tasks and the ability to perform those tasks are important determinants of occupation assignment.

\section{Youth Sociability and Adult Wages}

Trends in the importance of people tasks will affect the relative wages of workers with varying amounts of people skills. We use trends in the wages of workers, who are more likely to have people skills relative to those who are less likely to have people skills, to obtain an independent source of information about changes in the importance of people tasks in the labor market. To estimate the premium to people skills, we relate wages in adulthood to youth sociability using the NLSY79. Our empirical specification builds on (2), where the log wage of a person $i$ at time $t$ is

$$
\ln \left(w_{t i}\right)=\ln \left(w_{N}\right)_{t}+\ln \left(w_{P} / w_{N}\right)_{t} \pi_{P \mid \text { Sociabilit }_{i}}+\beta_{1} \text { OtherTasks }_{i t}+\beta_{2}{ }^{\prime} X_{i t}+\omega_{t}+v_{i}+\eta_{i t}^{O}+\varepsilon_{t i} .
$$

Here, $\ln \left(w_{i t}\right)$ denotes individual $i$ 's $\log$ wage at time $t$ and $\pi_{P \mid \text { Sociabilit }_{i}}$ gives the probability that someone has people skills, for which we proxy using the NLSY measures of sociability - self 
reports for age 6 and in adulthood and the number of clubs to which the respondent belonged in high school. The coefficient on sociability gives a measure of the premium to people skills at time $t$. In the specifications below, we assume that $\ln \left(w_{P} / w_{N}\right)_{t}$ changes linearly from 1979 (when the survey begins) until 1992 and again linearly from 1992 onward (the results are not sensitive to the choice of years). The term $\ln \left(w_{N}\right)_{t}$ is captured by year fixed effects. In addition, the model includes measures of the importance of other tasks in $i$ 's occupation at $t$ (OtherTasks $\left.{ }_{i t}\right)$; time varying individual characteristics (a quadratic in experience and education) given by $X_{i t}$; and time dummy variables $\left(\omega_{t}\right)$ which capture the wage level for people who do not have people skills, $\ln \left(w_{N}\right)_{t}$.

One concern with these estimates is that people who are more sociable may have other characteristics that raise their wages. To account for fixed individual differences in wages that may be correlated with our measures of people skills and people tasks, we include individual fixed effects $\left(v_{i}\right)$. These fixed effects will capture the direct effect of sociability on wages. Given that the returns to skill are generally increasing over this period, an increase in the people skills premium might be due to an increase in the return to unobserved skills, but such a bias would not be consistent with a downward break in the premium to people skills after 1992. Given that the data contain many observations for the same occupation, we include occupation random effects $\left(\eta_{i t}^{o}\right)$ as well as a classical error, $\varepsilon_{i t}{ }^{26}$

Table 4 reports the results. When youth sociability is measured using club memberships or sociability in early adulthood, the coefficient on sociability is found to increase until 1992 and then decline. $^{27}$ The NLSY cohort is aging over time. In order to control for changes in experience, the second panel also allows for a linear experience effect that breaks in 1992. With these controls included, we find a negative trend break in the importance of people skills after 1992 for all three measures and positive trends until 1992 for two of the three measures (sociability at age 6 remains statistically insignificant). The downward breaks after 1992 often exceed the pre-1992 trend, although the differences are not statistically significant. These estimates provide an independent source of evidence, one that is consistent with other work, that the importance of people skills increased until the early 1990s but flattened (or perhaps declined) in later years (e.g., Weinberger 2009).

\footnotetext{
26 The occupation fixed effects can be included even with individual fixed effects because people move across occupations. The estimates are not sensitive to the inclusion of occupation random effects.

${ }^{27}$ For sociability at age 6 , the trends are statistically insignificant.
} 


\section{People Skills and Labor-Market Outcomes of Underrepresented Groups}

Having validated our measures of the importance of people tasks and documented how people skills affect individual labor-market outcomes, we turn to the impact of people skills on the labor-market outcomes of underrepresented groups.

\section{Gender, Race, and Ethnicity in the United States}

Women report being more effective in people tasks than men (Borghans, ter Weel, and Weinberg 2008) and they report being members of more clubs in high school, ${ }^{28}$ which is consistent with Gilligan's (2001) work on gender differences. Experimental studies also find that women are more likely to cooperate than men in playing prisoner's dilemmas (Frank, Gilovich and Regan 1993 and Ortmann and Tichy 1999; Andreoni and Vesterlund 2001 find that women are more generous when it is costly). We therefore expect women to be more likely to enter jobs where people tasks are more important. Similarly, a minority population may be at a disadvantage when interacting with a majority population because of prejudice and/or because racial, ethnic, cultural, and linguistic differences pose a barrier to interpersonal interactions. This section presents estimates of how the employment of gender and race (black, and non-black) pairs varies across occupations as a function of the importance of people tasks. As indicated, we view the importance of people skills as being driven by computerization with the applicability of computer technologies varying across occupations. Data on the employment of the various groups are constructed from the 1980 and 1990 Census Public Use Micro Samples. Data on the importance of tasks are drawn from the 1977 and 1991 DOT.

The top panel of Table 5 reports cross-sectional estimates for the employment of each group in an occupation in 1980 on the importance of skills as measured in the 1977 DOT. These estimates are our empirical counterparts of equation (2) where the coefficient on the importance of people skills gives $\pi_{x \mid P}-\pi_{x \mid N}$ for $x \in\{B W, B M, N W, N M\}$. These estimates are from seemingly unrelated regressions. They indicate that occupations where people tasks are more important favor women and non-blacks. The figures in brackets give the implied effect of a one standard deviation change in the importance of people tasks. Along with language, which has an interactive component, physical, and specific skills, people skills are among the most important variables. Roughly 35 percent of workers

\footnotetext{
${ }^{28}$ Estimates from the NLSY79 show that after controlling for observed characteristics, women report being in .40 more clubs than men (standard error of .03).
} 
are non-black women, so a one standard deviation increase in the importance of people tasks would raise the employment share of non-black women by roughly 20 percent. People skills are essentially neutral toward black women. The coefficients for black men and non-black men are both negative and statistically significant but, in interpreting them, it is important to bear in mind that roughly 5 percent of workers are black men, while 55 percent of workers are non-black men. Thus, a one standard deviation increase in the importance of people tasks would lower the employment of nonblack men by slightly over 10 percent, but decrease the employment of black men by over 20 percent.

The bottom panel of the table reports estimates where the dependent variable is the change in the employment share of each group between the 1980 and 1990 Census and the independent variables are the change in the task variables between the 1977 and 1991 DOTs. The 1991 revision to the DOT was quite limited, almost surely understating the changes in job tasks and making the estimates less precise, but the results from the change regressions are similar to the cross-sectional results.

One concern with these estimates is that insofar as the various groups perform jobs differently, differences or changes in the employment shares of the various groups may drive the relationship between tasks and employment shares. To account for this bias, we have constructed the task variables among non-black men and estimated the models using three stage least squares (3SLS) using the tasks of white men as instruments for the overall task variables. The estimates, though less precise, are similar to those reported here.

To provide a sense of the magnitudes of the effect of changes in the importance of people tasks on the (derived) demand for workers based on race and gender, we estimate how acceleration in the importance of people tasks after 1977 and the deceleration after 1992 accelerated and then decelerated the demand shift for women and blacks. These estimates equal the estimated effect of people tasks on the employment shares of the 4 gender-race groups multiplied by the acceleration in 1977 and deceleration in 1992 in the importance of people tasks. Unfortunately, we only have reliable estimates of trends in the importance of people tasks arising from shifts between occupations. The analysis of German data, discussed above, indicates that the total shift is likely to be between 3.6 and 20 times the between-occupation shift.

Taking the lower bound value that the total shift is 3.6 times the between-occupation shift implies that if the wage structure had remained fixed, the 1977 acceleration in increasing importance of people tasks would have raised the employment of non-black women by roughly .36 percent per year and that the 1992 deceleration would have reduced it by .29 percent per year. The effects for 
black men are opposite in sign, but only slightly lower in magnitude - a .32 percent reduction in 1977 and a .25 increase in 1992. The effects on white men are considerably smaller than for black men - a .16 percent annual reduction in 1977 and a .14 percent annual increase in 1992 . The effects for black women are quite small. Over this time period, white women's employment is rising by roughly .7 percent per year; white men's employment is falling by roughly .7 percent per year; and black men's employment is rising by .4 percent per year. Setting aside the wage changes for the moment, the trend breaks we estimate are substantial relative to the underlying trends in employment.

\section{Demand for People Workers}

This section presents estimates of trends in the relative demand for people workers. The estimates are based on the wage and employment trends and cross-occupation employment regressions presented above. Thus, we generate an implied demand shift toward people workers that is independent of the time-series variation in the DOT measure of the importance of people tasks. Despite the different sources of these series, they are remarkably similar, supporting our hypothesis that trends in the importance of people tasks are driving changes in the labor markets of underrepresented groups.

\section{People Workers across Groups}

Our model outlines a framework to infer the demand for people workers using data on the employment and wages of gender-race groups. The first step is to obtain estimates of the share of people workers in each group. To do this, we use the preceding estimates of the effect of people tasks on the employment of the four gender race groups.

Combining the three independent equations from (4) (the fourth is redundant because the employment shares must add to 1) with the condition that the supply and demand for people skills have to be equal, $\pi_{P}=\frac{\pi_{P \mid x} n_{x}}{\sum_{\tilde{x}} n_{\tilde{x}}}$, yields four equations. Using data on the size of the four groups $\left(n_{g}\right)$, which are taken to be the means across all years and the share of people jobs ${ }^{29}$, there are four

\footnotetext{
${ }^{29}$ Estimating the share of people jobs requires converting our measure of people tasks to a discrete measure. We do this by comparing the mean importance of people tasks in the economy to the minimum and maximum across occupations, assuming that all jobs in the occupation where people tasks are most important are people jobs and that none of the jobs in the occupation where people skills are least important are people jobs. Now, 42 percent of jobs are people jobs.
} 
unknowns, the $\pi_{P \mid x}$, for which we can solve. Doing so, we get that the share of each group with people skills is, $\hat{\pi}_{P \mid N W}=.6466$ (standard error .0063); $\hat{\pi}_{P \mid N M}=.2944$ (standard error .0030); $\hat{\pi}_{P \mid B W}=.4307$ (standard error .0072); and $\hat{\pi}_{P \mid B M}=.1386$ (standard error .0057). Because they are derived from the estimated effect of people skills on the employment of the groups, the shares of the groups imputed to have people skills are ordered in the same way (i.e., non-black women the highest through black men the lowest).

\section{Trends in the Demand for People Workers}

Next, we use the constant elasticity of substitution demand framework to impute trends in the demand for people skills. We estimate the employment of people and non-people workers, $L_{P}$ and $L_{N}$, using these estimates of the share of workers in each group with people skills and the observed employment shares of the four gender-race groups. The implied relative employment of workers with people skills, $\ln \left(\frac{L_{P}}{L_{N}}\right)$ is shown in Figure 5. The supply flattens out in the early 1990s. Thus, in the absence of a deceleration in demand, we would expect the premium to people skills to increase at that point.

The model implies that the mean log wage for group $x$ at time $t$ is

$$
\overline{\ln \left(w_{t}^{x}\right)}=\ln \left(w_{N t}\right)\left(1-\pi_{P \mid x}\right)+\ln \left(w_{P t}\right) \pi_{P \mid x}=\ln \left(w_{N t}\right)+\ln \left(w_{P} / w_{N}\right)_{t} \pi_{P \mid x} .
$$

Here the endowments of the groups are assumed to remain constant.

We stack the four $\overline{\ln w_{t}^{g}}$ we have for each of the $T$ years in the sample and estimate $\overline{\ln w_{t}^{x}}=\beta_{t}+\gamma_{t} \pi_{P \mid x}+\varepsilon_{t}^{x}$.

Here the $\beta_{t}$ denote year fixed effects and $\gamma_{t}=\ln \left(w_{P t} / w_{N t}\right)$ denotes the year-specific coefficient on $\pi_{P \mid x}$ (taken from above), which gives the premium to people skills in year $t$. Intuitively, we estimate the premium to people skills in year $t$ from the difference in log wages between groups with more people skills and less people skills in that year. Doing so implies the relative price of people skills shown in Figure 6.

Using this wage series and the supply series in Figure 5, we back out the CES demand 
indices $\ln \left(\frac{\delta}{1-\delta}\right)$ from equation (1) for elasticities of substitution of $1,1.75$, and $2.5 .{ }^{30}$ The estimated relative demand series for people skills are shown in Figure 7. The imputed demand series for people workers relative to non-people workers is flat or declines until the mid-1970s, rises until the early 1990s and then is flat or declines. The size of the imputed demand shift increases with the elasticity assumed because higher elasticities place more weight on wage changes.

To investigate the relationship between trends in the demand for people workers and the importance of people tasks in Figure 3, we correlate the two (sets of) series. The correlations range from .833 (when the elasticity of substitution is assumed to be 2.5 ) to .851 (when the elasticity of substitution is assumed to be 1). Thus, the time series pattern in the importance of people tasks and the demand for people skills line up quite closely. It is important to bear in mind that these two series are estimated independently, from the time-variation in occupational employment shares on the one hand and the cross-occupation employment regressions and wage and employment trends for different groups of workers on the other. The close relationship strongly suggests a link between changes in the importance of people tasks and the labor markets of women and blacks.

Returning to the impacts on the wages of demographic groups and taking non-black men as the benchmark, we have that

$$
\overrightarrow{\ln \left(w_{t}^{x}\right)}-\overrightarrow{\ln \left(w_{t}^{N M}\right)}=\ln \left(w_{P} / w_{N}\right)_{t}\left(\pi_{P \mid x}-\pi_{P \mid N M}\right) .
$$

Our CES demand framework implies that a one percent increase in demand for people skills maps directly into a one percent increase in wages. Using the observed between-occupation increase in the importance of people skills after 1977 and our estimates of the $\pi_{P \mid x}$, implies that the increase in the importance of people skills increased the wages of non-black women relative to non-black men by 5.8 percent compared to an actual increase of 11.8 percent ; the wages of black women relative to non-black men by 2.2 percent compared to an actual increase of 5.5 percent; and decreased the wages of black men relative to non-black men by 2.6 percent compared to an actual decline of 3.8 percent. These estimates would tend to overstate the effects of increases in the importance of people skills because the supply of people skills accelerated by 7.9 percent over this period. On the other hand, the total increase in the importance of people skills is likely to be at least 3.6 times larger than

\footnotetext{
${ }^{30}$ We motivate our use of these values for the elasticities of substitution as follows. Weinberg (2000) estimates an elasticity of substitution between men and women of 2.4. We have estimated the elasticity of the demand for blacks using panel data on the nine Census divisions from 1963 to 2002, by regressing the log employment of blacks relative to non-blacks on the log wage of blacks relative to whites and division and time fixed effects. This regression yields an estimate for the elasticity of substitution of 1.027 with a standard error of .093.
} 
the between-occupation change. Thus, while the exact numbers depend on assumptions about the elasticity of substitution between people and non-people workers and the share of the increase in the importance of people skills that arises within versus between occupations, it is clear that increases in the importance of people skills can explain a large portion of trends in the gender and racial-wage gaps.

\section{Additional Evidence}

This section provides a range of additional evidence in favor of our hypothesis that the importance of people tasks is an important determinant of the labor-market outcomes of underrepresented groups, both at a point in time and in terms of changes over time. The estimates include data on a variety of groups in the United States and also for Britain and Germany. International comparisons are important because technological change implies similar trends across similar countries. And, pervasive changes can accentuate relative wages to changes (e.g., Berman, Bound, and Machin 1998).

\section{Other Race and Ethnicity in the United States}

Ethnic differences, like racial differences, may impede interactions, especially in the presence of prejudice. To get at this hypothesis, the left portion of Table 6 reports results for Hispanic men and women. The estimates in the top panel for the 1980 cross section show that occupations in which people tasks are more important have a lower employment of Hispanic men and (slightly) higher employment of Hispanic women. For Hispanic men, a one standard deviation increase in the importance of people tasks would reduce employment by 15 percent. Occupations where language is important also have lower employments of Hispanic men and a higher employment of Hispanic women (of course, the importance of language is likely to reflect the importance of interpersonal interactions). Estimates for changes between 1980 and 1990 shown in the bottom panel, are imprecise.

The right portion of the table reports results for other race individuals (non-white and nonblack). The 1980 cross-sectional results in the top panel indicate that occupations in which people tasks are more important employ fewer other race individuals, men or women (the estimates based on changes between 1980 and 1990 in the bottom panel are imprecise). Given that roughly 1.5 percent of the workforce is other race men, the coefficient implies that a one standard deviation increase in the importance of people tasks would decrease the employment of other race men by 
roughly 20 percent, an effect that is comparable to that for black men. For other race women a similar increase in the importance of people tasks would decrease employment by 7 percent. As above, we obtain similar estimates when we instrument for the task variables using the tasks used by white men.

\section{Immigrant Status and Language}

People with poor language skills will be at a comparative disadvantage in occupations that emphasize people tasks, especially if poor language skills are associated with less familiarity with a majority culture. The U.S. Census asks whether respondents "sometimes or always speak a language other than English at home" (Bureau of the Census 1993, B-24). The estimates presented in the first set of columns in Table 7 show that the importance of people tasks raises the employment share of people who do not speak a language other than English at home even after controlling for the importance of language. A one standard deviation increase in the importance of people tasks raises the relative employment of people who do not speak a language other than English at home by 1.2 percent. Given that 10 percent of the sample does not speak English at home, a one standard deviation increase in the importance of people tasks reduces their employment share by 12 percent.

People who report speaking a language other than English at home were asked about their ability to speak English. Column (2) takes as the dependent variable the employment share of people who speak a language other than English at home whose English speaking ability is very good (the highest category) relative to those whose English is not as good. The estimates show that a one standard deviation increase in the importance of people tasks raises the relative employment of people whose English is very good by 3.9 percent, roughly 10 percent of their employment share. ${ }^{31}$

Column (3) reports estimates from an analysis that takes the employment share of foreignborn workers (those born outside of the United States or its territories) in an occupation as the dependent variable. A one standard deviation increase in the importance of people tasks lowers the relative employment of immigrants by 1 percent, which is 14 percent of their overall share.

Taken together, these estimates suggest that increases in the importance of people tasks in an occupation affect the employment of underrepresented groups in that occupation. As people tasks become more important the relative employment of women and people with good English increases, but that of racial and ethnic minorities and immigrants declines. The effects of people tasks on these

\footnotetext{
${ }^{31}$ This result is related to the results from the Census in Lazear (1999), showing that the likelihood that an immigrant speaks English is inversely related to the proportion of the local population that speaks their native language.
} 
variables are generally much larger and statistically stronger than the effects of other tasks and skills, which are often only of minor importance.

\section{International Evidence: Britain and Germany}

This section documents a final set of estimates of the effect of people tasks on the employment share of women in Britain and Germany. Data on ethnic minorities are absent in the data sources at our disposal. We regress women's employment share in an occupation on job tasks and controls for the experience and education distribution in that occupation.

Table 8 reports results for Britain. Data on women's employment and the importance of tasks are constructed from the 1997, 2001, and 2006 British Skills Surveys. The first three columns report the means and standard deviations of the task variables. Our goal is to relate (changes in) women's employment share to (changes in) the task variables. Women report that people tasks are more important on their jobs than men, so exogenous changes in women's employment will bias our estimates of the effect of people skills up. To account for this bias, we instrument for the (change in the) set of task variables by the (change in the) set of the task variables among men.

Cross-section estimates for the three years (in columns 4-6) show that women have higher employment shares in occupations where people tasks are more important. To probe the robustness of our estimates, the last column reports results for the change in women's employment share on the change in the task variables between 1997 and 2006. While some of the task variables become insignificant in this change regression, the importance of people tasks remains positive and statistically significant. The increased importance of people tasks over the four years from 1997 to 2001 is estimated to have raised women's employment share by 3.5 percent to 6 percent (depending on the specification). The bottom panel of the table shows that women's employment share increased by 5.1 percent over this period, so these changes are large relative to the observed increase in women's employment. The gender-wage gap closes by about 5 percent in Britain over this period (e.g., OECD 2010).

Table 9 reports analogous results for Germany. Data on women's employment share and the importance of tasks are constructed from the 1979, 1985, 1991, and 1998 BIBB/IAB. Panel A reports the means and standard deviations of all tasks. Panel B reports regression estimates. In both random effects and fixed effects models, increases in the importance of people tasks are found to increase women's employment share, with the choice of estimation method having little impact on the coefficient. The last set of results instruments for the change in the importance of all of the task 
variables by the change in the task variables among men. These estimates are virtually identical to those estimated without the instrument (although the standard errors are larger). The increase in the importance of people tasks over this period in Germany would have raised the employment share of women by between 4 and 4.7 percentage points. The employment of women increased by 7.7 percent in Germany over this period (their relative wages fell by 1 percent). Thus, the increase in employment of women implied by the regressions is quite large relative to the observed increase in employment.

\section{Conclusion}

Despite informal arguments that people skills are important for understanding individual outcomes and are becoming more important, economists have done little to analyze their economic consequences. This paper provides a first step in this direction, developing a unified model to understand the labor-market consequences of people skills and demonstrating the relationship between people skills and labor-market outcomes.

We test our model's implications using a range of data sources from the United States, Britain, and Germany and find that sociability at young ages is positively correlated with the importance of people tasks in a worker's adult occupation. We also find that computers initially made people tasks more important, but that this relationship has weakened over time. With respect to labor-market outcomes of underrepresented groups our results suggest that occupations in which people tasks are more important employ more women relative to men, but fewer racial, ethnic, and linguistic minorities and fewer immigrants.

Finally, our results shed new light on changes in the labor-market outcomes of underrepresented groups in the United States over the last four decades, suggesting that the large increase in the importance of people tasks at work from the late 1970s to the early 1990s helps to explain the rapid decline in the gender-wage gap over this period. Similarly, the slowing convergence of the gender-wage gap since the mid-1990s, seems to be consistent with a slowdown in the growth rate of the importance of people tasks. Our estimates are also consistent with the opposite trends in the black-white wage gap. 


\section{References}

Acemoglu, Daron, and David H. Autor. 2011. Skills, tasks and technologies: Implications for employment and earnings. In Orley Ashenfelter and David E. Card (Eds.), Handbook of Labor Economics, Vol. 4, pp. 1043-72. Amsterdam: Elsevier.

Altonji, Joseph G. and Rebeccca M. Blank. 1999. Race and gender in the labor market. In Orley Ashenfelter and David E. Card (Eds.), Handbook of Labor Economics, Vol. 3C, pp. 31433259. Amsterdam: Elsevier.

Andreoni, James and Lise Vesterlund. 2001. Which is the Fairer Sex? Gender Differences in Altruism. Quarterly Journal of Economics, 116(1): 293-312.

Ashton, David, Bryn Davies, Alan Felstead and Francis Green. 1998. Work Skills in Britain. SKOPE Monograph No. 1. University of Oxford.

Autor, David H. and David Dorn. 2009. Inequality and Specialization: The Growth of Low-Skilled Service Employment in the United States. NBER Working Paper No. 15150.

Autor, David H. and Michael J. Handel. 2009. Putting Tasks to the Test: Human Capital, Job Tasks and Wages. NBER Working Paper No. 15116.

Autor, David H., Lawrence F. Katz and Melissa S. Kearney. 2006. The Polarization of the U.S. Labor Market. American Economic Review, 96(2): 189-194.

Autor, David H., Frank Levy, and Richard J. Murnane. 2003. The Skill Content of Recent Technological Change: An Empirical Exploration. Quarterly Journal of Economics, 118(4): 1279-1333.

Bacolod, Marigee P., and Bernardo S. Blum. 2010. Two Sides of the Same Coin. U.S. "Residual" Inequality and the Gender Gap. Journal of Human Resources, 45(1): pp. 197-242.

Bayard, Kimberly, Judith Hellerstein, David Neumark, and Kenneth R. Troske. 2003. New Evidence on Sex Segregation and Sex Differences in Wages from Matched Employer-Employee Data. Journal of Labor Economics, 21: 887-922.

Becker, Gary S. 1971. The Economics of Discrimination. Chicago, IL: University of Chicago Press.

Berman, Eli, John Bound, and Stephen Machin. 1998. Implications of Skill-Biased Technological Change: International Evidence. Quarterly Journal of Economics, 113(4): 1245-1279.

Black, Sandra E., and Elizabeth Brainerd. 2004. Importing Equality? The Impact of Globalization on Gender Discrimination. Industrial and Labor Relations Review, 57: 540-559.

Black, Sandra E., and Alexandra Spitz-Oener. 2010. Explaining Women's Success: Technological Change and the Skill Content of Women's Work. Review of Economics and Statistics, 92(1): 187-194.

Blau, Francine D., Andrea H. Ferber, and Anne E. Winkler. 2006. The Economics of Women, Men, and Work. Upper Saddle River, NJ: Pearson Prentice Hall.

Blau, Francine D., and Lawrence M. Kahn. 1997. Swimming Upstream: Trends in the Gender Wage Differential in the 1980s. Journal of Labor Economics, 15(1): 1-42.

Blau, Francine D., and Lawrence M. Kahn. 2004. The U.S. Gender Pay Gap in the 1990s: Slowing Convergence. NBER Working Paper No. 10853. 
Bloom, Nicholas, Luis Garicano, Raffaella Sadun, and John Van Reenen. 2009. The Distinct Effect of Information Technology and Communication Technology on Firm Organization. NBER Working Paper No. 14975.

Bonsor, Kevin, and Ryan Johnson. 2001. How Facial Recognition Systems Work. HowStuffWorks.com.

Borghans, Lex, and Bas ter Weel. 2004. What Happens When Agent $T$ Gets a Computer? The Labor Market Impact of Cost Efficient Computer Adoption. Journal of Economic Behavior and Organization, 54: 137-151.

Borghans, Lex, and Bas ter Weel. 2006. The Division of Labour, Worker Organisation, and Technological Change. Economic Journal, 116: F45-F72.

Borghans, Lex, Angela L. Duckworth, James J. Heckman, and Bas ter Weel. 2008. The Economics and Psychology of Personality Traits. Journal of Human Resources, 43(4): 972-1059.

Borghans, Lex, Bas ter Weel, and Bruce A. Weinberg. 2008. Interpersonal Styles and Labor Market Outcomes. Journal of Human Resources, 43(4): 815-858.

Borjas, George. 1982. The Earnings of Male Hispanic Immigrants in the United States. Industrial and Labor Relations Review, 35: 343-353.

Borjas, George J. 1995. Assimilation and Changes in Cohort Quality Revisited: What Happened to Immigrant Earnings in the 1980s? Journal of Labor Economics, 13: 201-245.

Borjas, George J. and Lawrence F. Katz. 2005. The Evolution of the Mexican-Born Workforce in the United States. NBER Working Paper No. 11281.

Bound, John, and Richard B. Freeman. 1992. What Went Wrong? The Erosion of Relative Earnings and Employment Among Young Black Men in the 1980s. Quarterly Journal of Economics, 107(1): 201-232.

Bowles, Samuel and Herbert Gintis. 1976. Schooling in Capitalist America: Educational Reform and the Contradictions of Economic Life. New York NY: Basic Books.

Bresnahan, Timothy F. and Shawn Greenstein. 1996. Technical Progress and Co-Invention in Computing and in the Uses of Computers. Brookings Papers on Economic Activity: Microeconomics, 1-77.

Brown, Charles. 1984. Black-White Earnings Ratios Since the Civil Rights Act of 1964: The Importance of Labor Market Dropouts. Quarterly Journal of Economics, 99(1): 31-44.

Brown, Charles, and Mary Corcoran. 1997. Sex-Based Differences in School Content and the Male/Female Wage Gap. Journal of Labor Economics, 15: 431-465.

Card, David, and Alan B. Krueger. 1992. School Quality and Black-White Relative Earnings: A Direct Assessment. Quarterly Journal of Economics, 107(1): 151-200.

Card, David, and Alan B. Krueger. 1993. Trends in Relative Black-White Earnings Revisited. American Economic Review, 83(1): 85-91.

Card, David and Thomas Lemieux. 1994. Changing Wage Structure and Black-White Differentials Among Men and Women: A Longitudinal Analysis. American Economic Review, 84(1): 2933.

Carnegie, Dale. 1936. How to Win Friends and Influence People. New York NY: Simon and Schuster. 
Chandra, Amitabh. 2000. Labor Market Dropouts and the Racial Wage Gap. American Economic Review, 90: 333-338.

Chandra, Amitabh. 2003. Is the Convergence in the Racial Wage Gap Illusory? NBER Working Paper No. 9476.

Collins, William J. 2001. The Labor Market Impact of State-Level Anti-Discrimination Laws, 19401960. NBER Working Paper No. 8310.

Committee on Occupational Classification and Analysis of the National Academy of Science. Dictionary of Occupational Titles (DOT): Part I - Current Population Survey, April 1971, Augmented with DOT Characteristics and Part II - Fourth Edition Dictionary of DOT Scores for 1970 Census Categories (1981), distributed by the ICPSR.

Cutler, David M., and Edward L. Glaeser. 1997. Are Ghettos Good or Bad? Quarterly Journal of Economics, 107: 827-872.

Cutler, David M., Edward L. Glaeser, and Jacob L. Vigdor. 1999. The Rise and Decline of the American Ghetto. Journal of Political Economy, 107: 455-506.

Dayal, Aman. 2006. Speech recognition on handheld devices. Downloaded from: http://tools.cotton.crc.org.au/cl2/ScoutingTools/Reports/CDD\%204.1\%20$\%$ 20SpeechRecognition.pdf on November 2, 2010.

Donohue, John J., and James J. Heckman. 1991. Continuous versus Episodic Change: The Impact of Affirmative Action and Civil Rights Policy on the Economic Status of Blacks. Journal of Economic Literature, 29: 1603-1644.

Donohue, John J., James J. Heckman, and Petra E. Todd. 2002. The Schooling of Southern Blacks: The Roles of Legal Activism and Private Philanthropy, 1910-1960. Quarterly Journal of Economics, 117(1): 225-268.

Entwistle, Marcia Seivert. 2003. The Performance of Automated Speech Recognition Systems Under Adverse Conditions of Human Exertion. International Journal of Human-Computer Interaction, 16: 127-140.

Felstead, Alan, Francis Green, and Duncan Gallie. 2002. Work Skills in Britain 1986-2001. Nottingham, DfES Publications, May.

Felstead, Alan, Duncan Gallie, Francis Green and Ying Zhou. 2007. Skills at Work. SKOPE Working Paper, Oxford University.

Fortin, Nicole M. 2008. The Gender Wage Gap among Young Adults in the United States: The Importance of Money versus People. Journal of Human Resources, 43(4): 884-918.

Freeman, Richard B. 1973. Changes in the Labor Market for Black Americans. Brookings Papers on Economic Activity, 2: 67-120.

Gardner, Howard. 1983. Frames of Mind: The Theory of Multiple Intelligences. New York, NY: Basic Books.

Gathmann, Cristina and Uta Schönberg. 2010. How General Is Human Capital? A Task-Based Approach. Journal of Labor Economics, 28(1): 1-49.

Gilligan, Carol. 2001. In A Different Voice: Psychological Theory and Women's Development. Cambridge, MA: Harvard University Press.

Goldin, Claudia. 1990. Understanding the Gender Gap. New York, NY: Oxford University Press. 
Goldin, Claudia. 2002. The Rising (and then Declining) Significance of Gender. NBER Working Paper No. 8915.

Goldin, Claudia. 2004a. The Long Road to the Fast Track: Career and Family. NBER Working Paper No. 10331.

Goldin, Claudia. 2004b. From the Valley to the Summit: The Quiet Revolution that Transformed Women's Work. NBER Working Paper No. 10335.

Goldin, Claudia, and Lawrence F. Katz. 2002. The Power of the Pill: Oral Contraceptives and Women's Career and Marriage Decisions. Journal of Political Economy, 110(3): 730-770.

Goldstein, Jill M., Larry J. Siedman, Nicholas J. Horton, Nikos Makris, David N. Kennedy, Verne S. Caviness, Jr., Stephen V. Faraone and Ming T. Tsuang. 2001. Normal Sexual Dimorphism of the Adult Human Brain Assessed by In Vivo Magnetic Resonance Imaging. Cerebral Cortex 11-6, pp. 490-497.

Goldsmith, Arthur H., Jonathan R. Veum and William Darity Jr. 1997. The Impact of Psychological and Human Capital on Wages. Economic Inquiry, 35: 815-829.

Hamermesh, Daniel S., and Jeff E. Biddle. 1994. Beauty and the Labor Market. American Economic Review, 84: 1174-1194.

Heckman, James J. 1974. Effects of Child-Care Programs on Women's Work Effort. Journal of Political Economy, 82: S136-S163.

Heckman, James J., Thomas M. Lyons, and Petra E. Todd. 2000. Understanding Black-White Wage Differentials, 1960-1990. American Economic Review, 90: 344-349.

Heckman, James J. and Yona Rubinstein. 2001. The Importance of Noncognitive Skills: Lessons from the GED Test Program. American Economic Review, 91(2): 145-149.

Holzer, Harry J. and Keith R. Ihlanfeldt. 1998. Customer Discrimination and Employment Outcomes for Minority Workers. Quarterly Journal of Economics, 108: 835-868.

Jaynes, Gerald D. 1990. The Labor Market Status of Black Americans: 1939-1985. Journal of Economic Perspectives, 4(1): 9-24.

Juhn, Chinhui. 1992. Decline in Male Labor Market Participation: The Role of Declining Market Opportunities. Quarterly Journal of Economics, 107(1): 79-121.

Juhn, Chinhui, Kevin M. Murphy, and Brooks Pierce. 1991. Accounting for the Slowdown in BlackWhite Wage Convergence. In M. Kosters (Ed.), Workers and Their Wages: Changing Patterns in the United States, pp. 107-143. Washington DC: American Enterprise Institute Press.

Kolb, Bryan, and Ian Q. Whishaw. 1985. Fundamentals of Human Neuropsychology. New York NY: Freeman and Company.

Krueger, Alan B., and David Schkade. 2008. Sorting in the Labor Market: Do Gregarious Workers Flock to Interactive Jobs? Journal of Human Resources, 43(4): 859-883.

Kuhn, Peter, and Catherine Weinberger. 2005. Leadership Skills and Wages. Journal of Labor Economics, 28: 395-436.

Lazear, Edward P. 1999. Culture and Language. Journal of Political Economy, 107: S95-S126.

Lee, Donghoon and Kenneth I. Wolpin. 2006. Intersectoral Labor Mobility and the Growth of the Service Sector. Econometrica, 74(1): 1-46. 
Mulligan, Casey B., and Yona Rubinstein. 2004. The Closing Gender Gap as a Roy Model Illusion. NBER Working Paper No. 10892.

Mulligan, Casey B., and Yona Rubinstein. 2008. Selection, Investment, and Women's Relative Wages Over Time. Quarterly Journal of Economics, 123(4): 1061-1110.

National Academy of Sciences, Committee on Occupational Classification and Analysis. 1981. Fourth Edition Dictionary of DOT Scores for 1970 Census Categories. ICPSR Document No. 7845, Ann Arbor, MI.

Neal, Derek. 2004. The Measured Black-White Wage Gap Among Women Is Too Small. Journal of Political Economy, 107: S1-S28.

Neal, Derek, and William R. Johnson. 1996. The Role of Premarket Factors in Black-White Wage Differences. Journal of Political Economy, 106: 869-895.

OECD. LMF1.5: Gender pay gaps for full-time workers and earnings differentials by educational attainment. http://www.oecd.org/dataoecd/29/63/38752746.pdf. Accessed on July 23, 2010.

Osborne, Melissa. 1999. Personality and Labor Market Success. Working paper, University of Massachusetts.

Persico, Nicola, Andrew Postlewaite, and Dan Silverman. 2004. The Effect of Adolescent Experience on Labor Market Outcomes: The Case of Height. Journal of Political Economy, 107: 1019-1053.

Prasad, Suraj. 2009. Task Assignments and Incentives: Generalists versus Specialists. Rand Journal of Economics, 40: 380-403.

Priebe, John A., Joan Heinkel, and Stanley Greene. 1972. 1970 Occupation and Industry Classifications in Terms of their 1960 Occupation an Industry Elements. Census Bureau Technical Paper No. 26.

Rumberger, Russell W. 1981. The Changing Skill Requirements of Jobs in the U.S. Economy. Industrial and Labor Relations Review, 34: 578-590.

Smith, James P. 1993. Affirmative Action and the Racial Wage Gap. American Economic Review, 83(2): 79-84.

Smith, James P., and Finis R. Welch. 1977. Black-White Earnings and Employment: 1960-1970. American Economic Review, 67: 323-338.

Smith, James P., and Finis R. Welch. 1984. Affirmative Action and Labor Markets. Journal of Labor Economics, 2: 269-301.

Smith, James P., and Finis R. Welch. 1989. Black Economic Progress After Myrdal. Journal of Economic Literature, 26: 519-564.

Spenner, Kenneth I. 1990. Skill: Meaning, Methods and Measures. Work and Occupations, 17: 399421.

Spitz-Oener, Alexandra. 2006. Technical Change, Job Tasks, and Rising Educational Demands: Looking Outside the Wage Structure. Journal of Labor Economics, 24: 235-270.

Sternberg, Robert J. 1984. Toward a Triarchic Theory of Human Intelligence. The Behavioral and Brain Sciences, 7: 269-315.

Trejo, Stephen. 1997. Why do Mexican Americans Earn Low Wages? Journal of Political Economy, 105: 1235-1268. 
Turner, Charles F. and Daniel C. Martinez. 1977. Socioeconomic Attainment and the Machiavellian Personality. Sociometry, 40: 325-336.

U.S. Department of Labor, Manpower Administration. 1972. Handbook for Analyzing Jobs. Washington, DC.

U.S. Department of Labor, Employment and Training Administration. 1977. Dictionary of Occupational Titles: Fourth Edition. Washington, DC.

U.S. Department of Labor, Employment and Training Administration. 1991. Dictionary of Occupational Titles: Revised Fourth Edition. Washington, DC.

U.S. Department of Labor, U.S. Employment Service, and the North Carolina Occupational Analysis Field Center. 1991 (1994). Dictionary of Occupational Titles: Revised Fourth Edition. Distributed by the ICPSR.

Urzua, Sergio. 2008. Racial Labor Market Gaps: The Role of Abilities and Schooling Choices. Journal of Human Resources, 43(4): 919-971.

Weinberg, Bruce A. 2000. Computer Use and the Demand for Female Workers. Industrial and Labor Relations Review, 53: 290-308.

Weinberger, Catherine. 2009. Quantifying the Growing Importance of 'Soft Skills' in the Labor Market. Working Paper.

Welch, Finis R. 2000. Growth in Women's Relative Wages and in Inequality among Men: One Phenomenon or Two? American Economic Review, 90(2): 444-449.

Williams, Mark. 2007. Better Face-Recognition Software. Technology Review. May 30. 
Figure 1. Gender and Race Gaps in Earnings
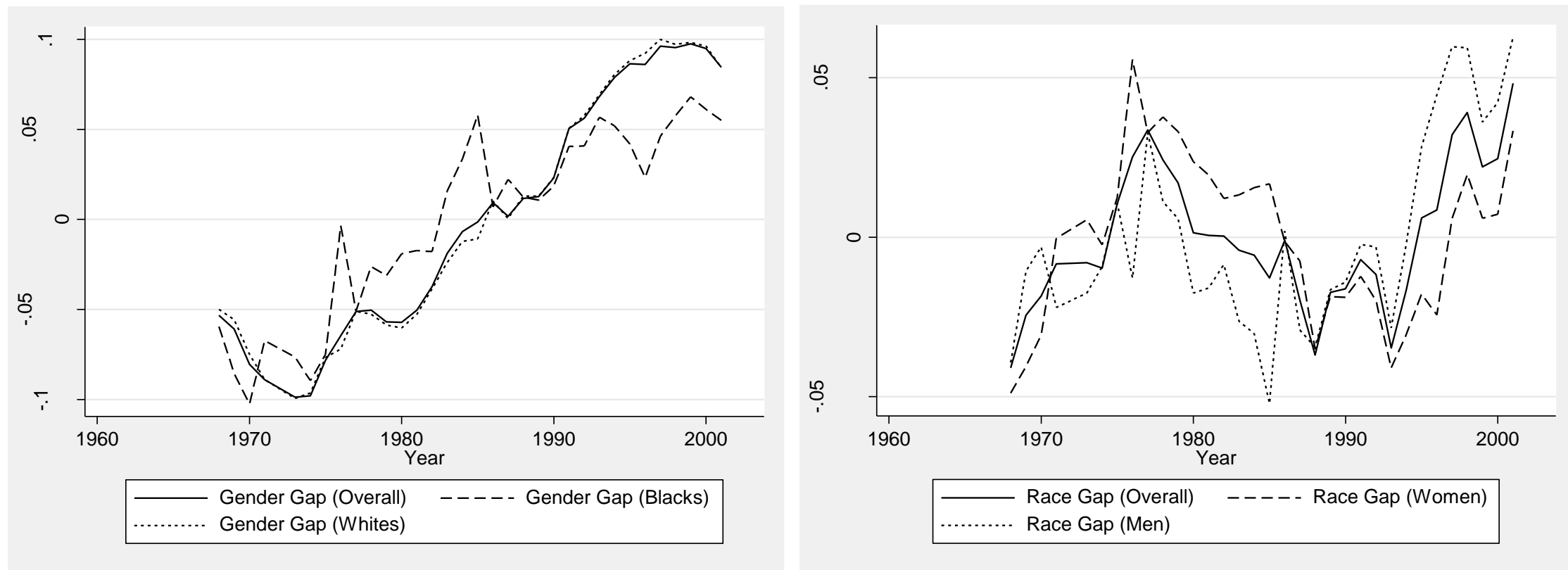

Note: Weekly earnings for full-time, full year, workers from the CPS March supplements, adjusted for educational and experience (fourth order polynomial) and selection into or out of employment, including incarceration (details of the procedures are described in Appendix A.2). Normalized to have a mean of zero. 
Figure 2. Importance of People Tasks

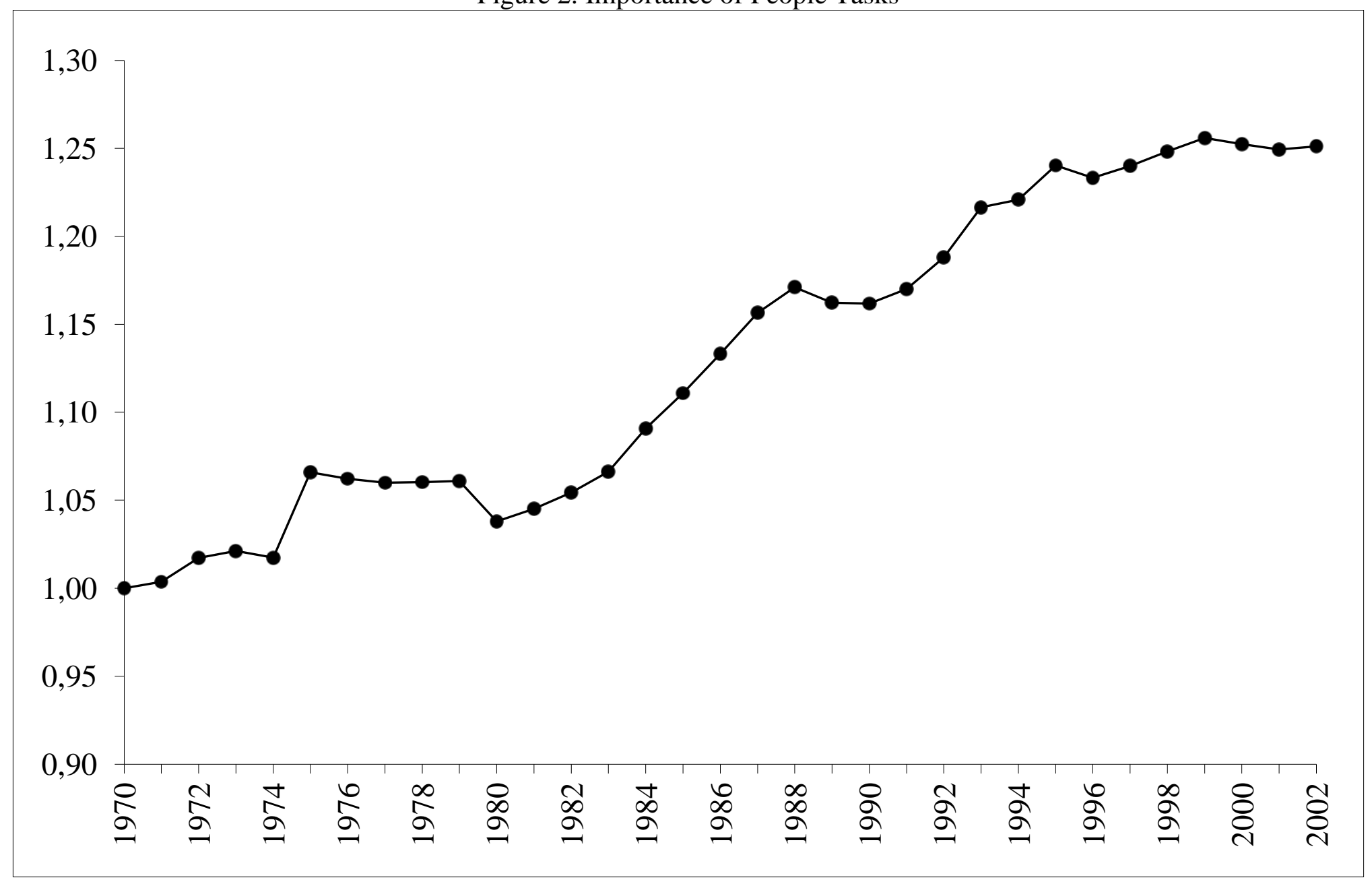

Note: Series gives the between-occupation trend in the importance of people tasks, constructed using 1977 DOT task measures for each occupation merged into employment data from the CPS. The series is constructed by taking a weighted average of the importance of people tasks across all occupations in each year where occupations are weighted by their employment in that year. See the Data Appendix for the definition of the DOT task measures $(1970=1)$. 
Figure 3. Employment of Women and Blacks

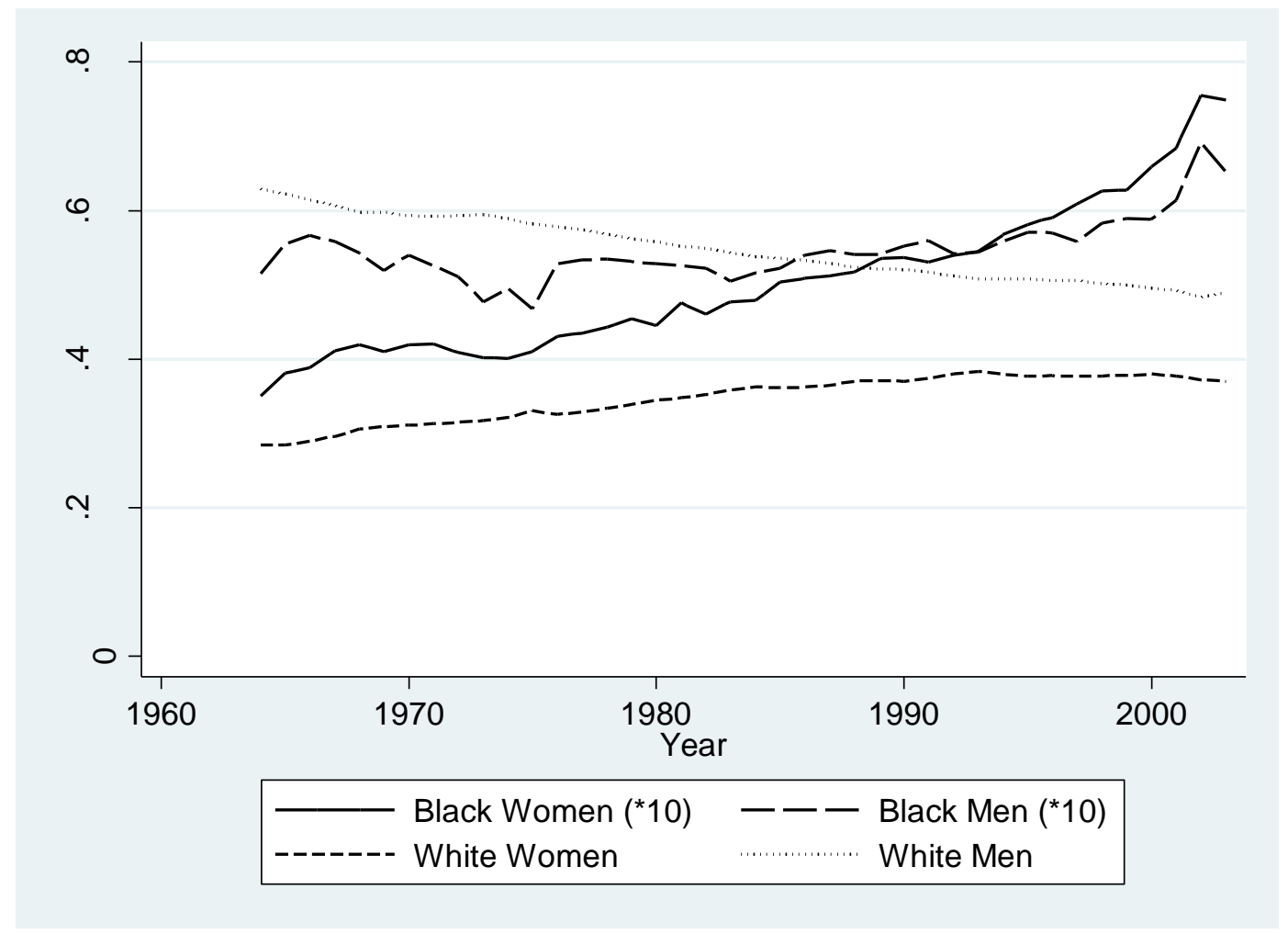

Note: Employment weighted by hours and weeks worked, from the CPS March supplements. 
Figure 4. Trends in the Importance of Non-People Tasks
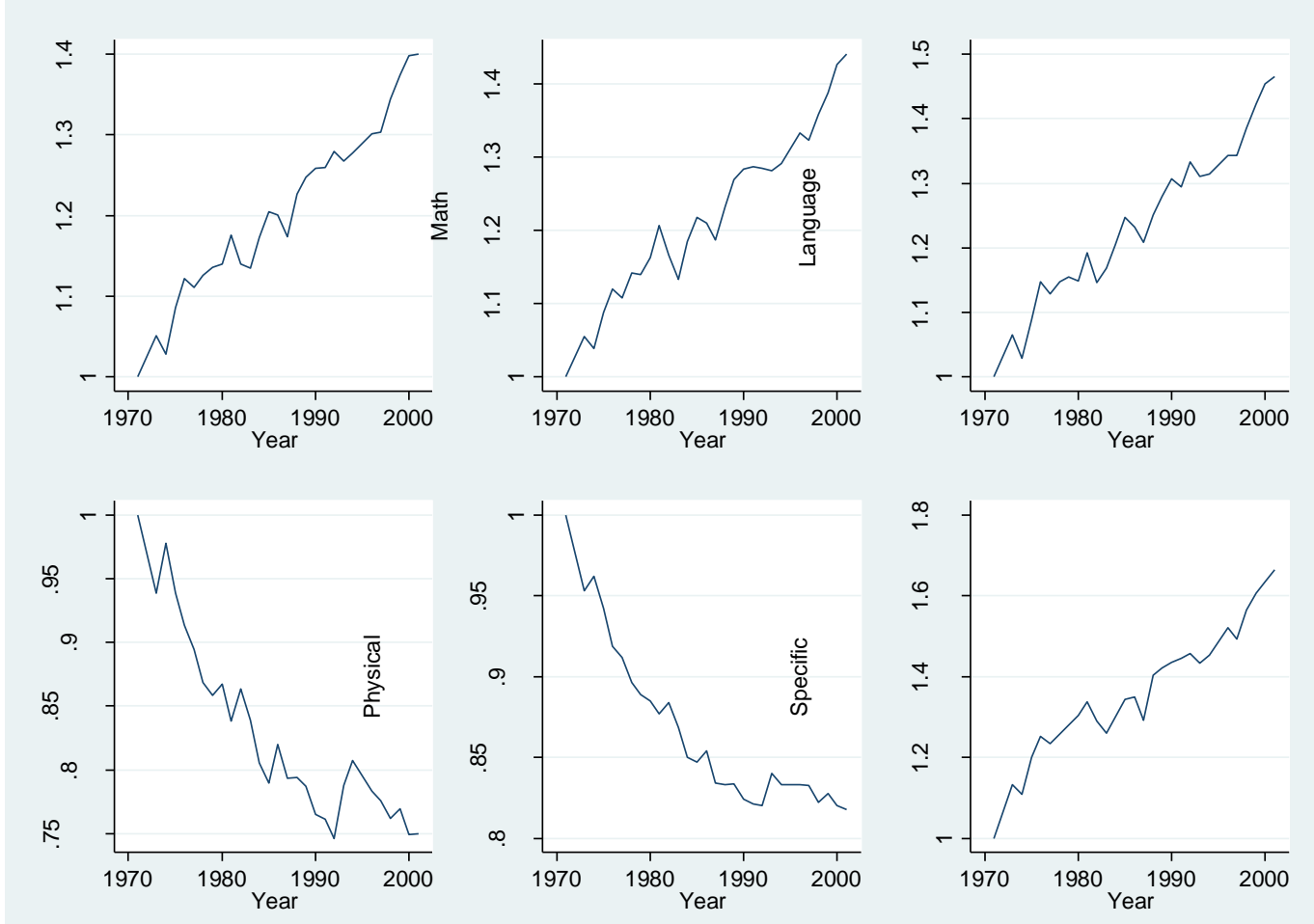

Note: Series gives the between-occupation trend in the importance of various tasks, constructed using 1977 DOT task measures for each occupation merged into employment data from the CPS. The series is constructed by taking a weighted average of the importance of each task across all occupations in each year where occupations are weighted by their employment in that year. See the Data Appendix for the definition of the DOT task measures $(1971=1)$. 
Figure 5. Relative Supply of Workers with People Skills.

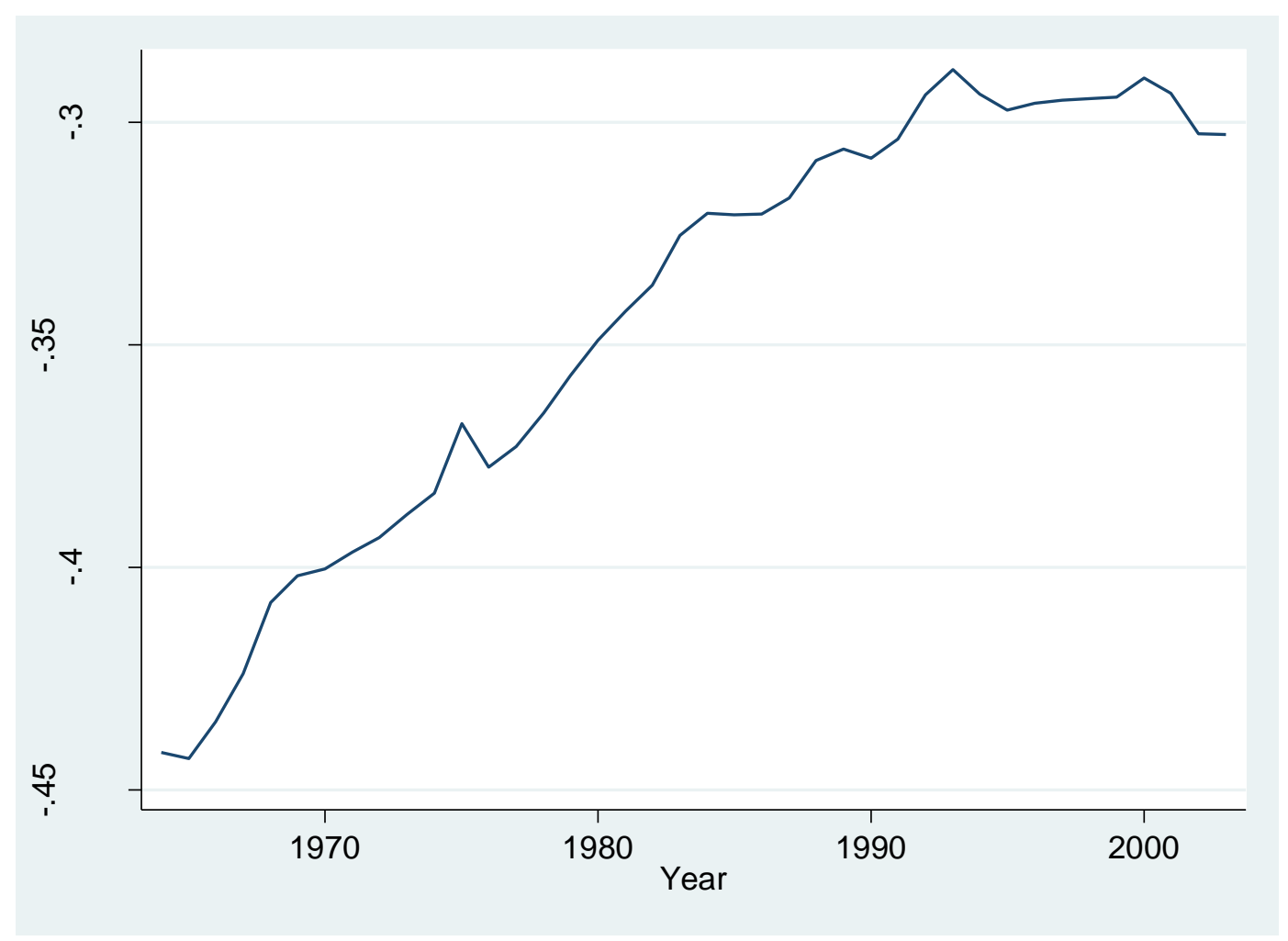

Note. The figure shows the estimated log employment of workers with people to workers without people skills based on the employment shares of workers in 4 gender-race groups and the share of workers in each group estimated "to have people skills." 
Figure 6. People Skills Premium.

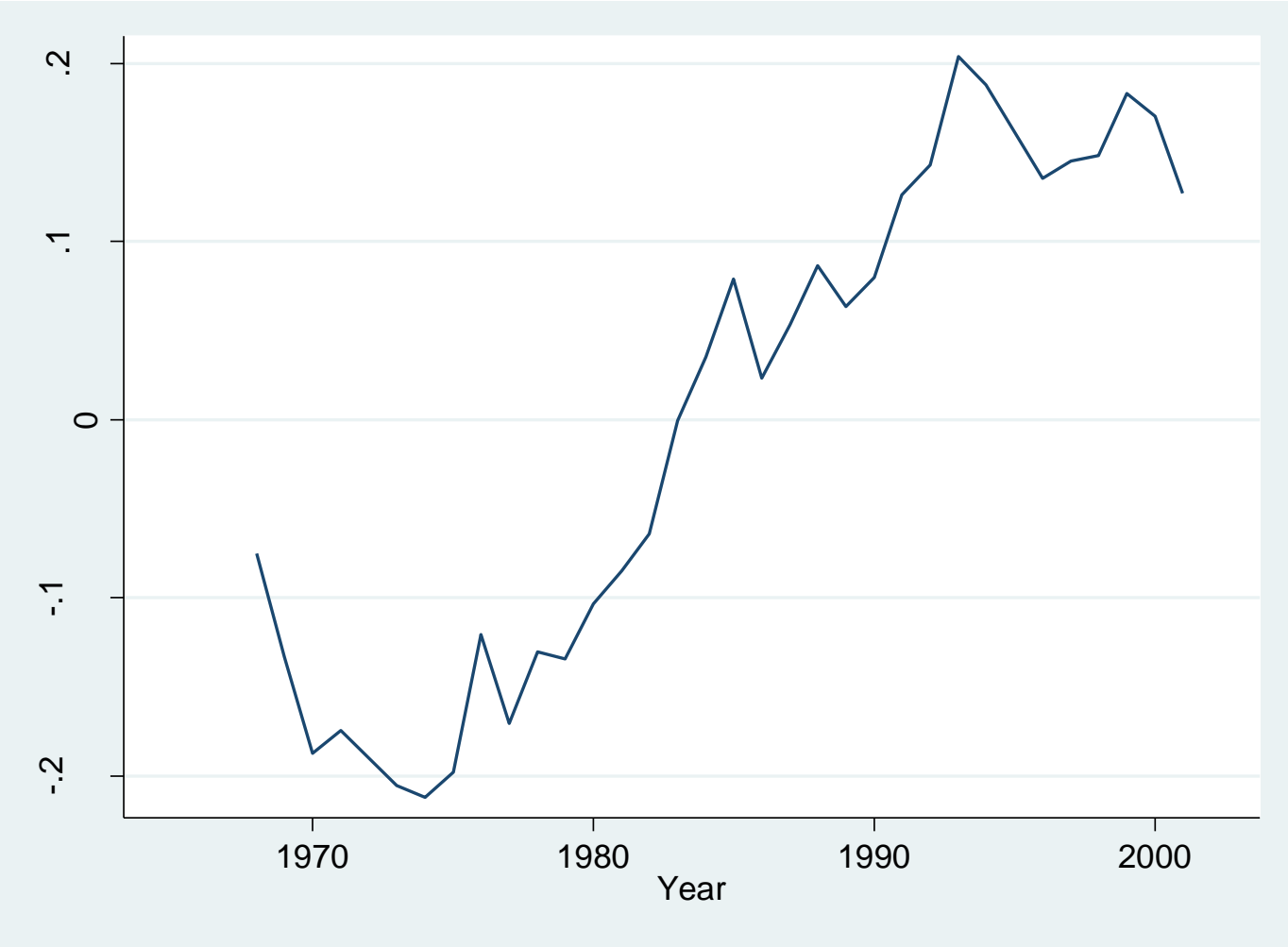

Note. People skills premium estimated from wage regressions. 
Figure 7. Relative Demand Series for Workers with People Skills.

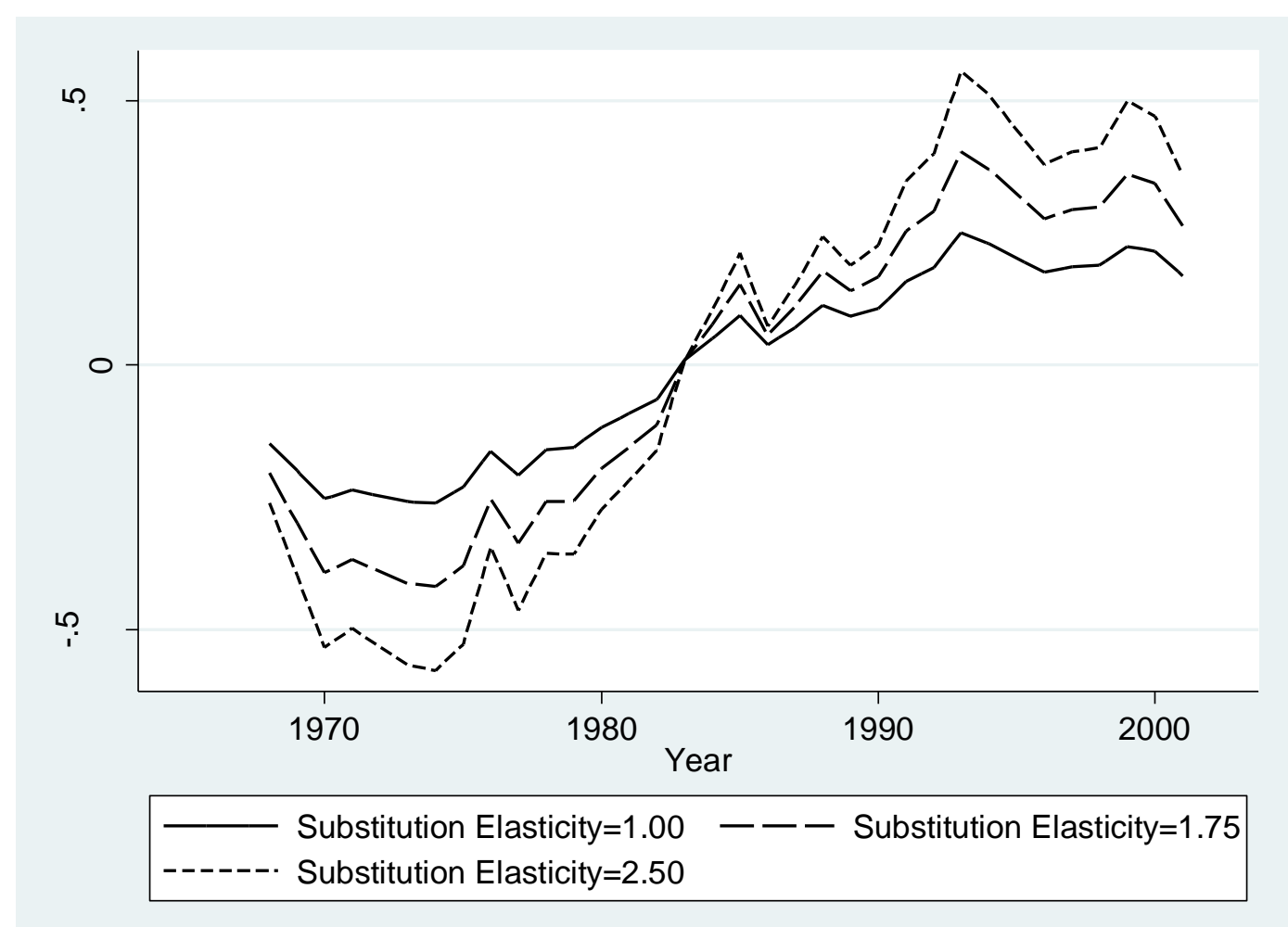

Note: Constant elasticity of substitution relative demand series for workers with people skills, based on the relative employment and relative wage series in Figures 5 and 6 for various elasticities of substitution. 
Table 1

Changes in the Importance of People Tasks Related to Changes in Computerization in Britain and Germany

(Dependent Variable: (Change in) People Tasks)

\begin{tabular}{|c|c|c|c|c|c|}
\hline Country & UK & UK & Germany & Germany & Germany \\
\hline Period & $1997-2001$ & $2001-2006$ & $1979-1985$ & $1985-1991$ & $1991-1998$ \\
\hline Change in Computer & .577 & .379 & .151 & .127 & -.030 \\
\hline Use & $(.042)$ & $(.030)$ & $(.005)$ & $(.002)$ & $(.002)$ \\
\hline $\begin{array}{ll}\text { Number } & \text { of } \\
\text { Occupations } & \end{array}$ & 293 & 279 & 83 & 82 & 82 \\
\hline
\end{tabular}

Note: All regressions are OLS and weighted by occupation size. All regressions include (unreported) controls for the education and gender mix of each occupation. The inclusion of these covariates does not change the estimation results. The coefficients show the impact of changes in computer use on changes in the importance of people tasks over the period shown. For Britain the data are taken from the BSS. For Germany the data come from the BIBB/IAB database. See the Data Appendix for a detailed discussion of the construction of the variables. 
Table 2

The Relationship between Sociability and the Importance of Job Tasks in Current Occupation in the United States (Dependent Variables: Importance of Job Tasks)

\begin{tabular}{|c|c|c|c|c|c|c|c|c|c|c|}
\hline \multirow{3}{*}{ Dependent Variable } & \multirow{2}{*}{$\begin{array}{c}\text { St.Dev. of } \\
\text { Dep. Variable }\end{array}$} & \multicolumn{3}{|c|}{ Sociability at Age Six } & \multicolumn{3}{|c|}{ Sociability in Early Adulthood } & \multicolumn{3}{|c|}{ Clubs } \\
\hline & & & & & & & & & & \\
\hline & $(1)$ & $(2)$ & (3) & (4) & $(5)$ & $(6)$ & $(7)$ & $(8)$ & $(9)$ & $(10)$ \\
\hline People Tasks & 2.329 & 0.114 & $(0.026)$ & {$[0.045]$} & 0.196 & $(0.035)$ & {$[0.056]$} & 0.050 & $(0.022)$ & {$[0.025]$} \\
\hline Reasoning & 0.898 & 0.019 & $(0.008)$ & [0.019] & 0.023 & $(0.011)$ & {$[0.017]$} & 0.029 & $(0.007)$ & {$[0.038]$} \\
\hline Math & 1.003 & 0.009 & $(0.009)$ & {$[0.008]$} & 0.016 & $(0.013)$ & {$[0.011]$} & 0.020 & $(0.008)$ & [0.023] \\
\hline Language & 1.116 & 0.026 & $(0.010)$ & {$[0.022]$} & 0.034 & $(0.013)$ & {$[0.020]$} & 0.034 & $(0.008)$ & {$[0.036]$} \\
\hline Strength & 0.687 & -0.006 & $(0.008)$ & {$[0.008]$} & -0.023 & $(0.010)$ & {$[0.022]$} & -0.006 & $(0.006)$ & {$[0.010]$} \\
\hline Physical Tasks & 0.289 & -0.001 & $(0.003)$ & {$[0.002]$} & -0.011 & $(0.004)$ & {$[0.025]$} & -0.003 & $(0.003)$ & [0.013] \\
\hline Specific Training & 1.594 & 0.037 & $(0.015)$ & {$[0.021]$} & 0.050 & $(0.020)$ & {$[0.021]$} & 0.045 & $(0.012)$ & {$[0.033]$} \\
\hline
\end{tabular}

Note: All data taken from the NLSY79, except for the task measures in the current occupation. These are three-digit occupational averages from the 1977 Dictionary of Occupational Titles merged into the NLSY79. All regressions include person random effects and control for gender, education, a quadratic in experience, race, Hispanic background, the score on the Armed Forces Qualifying Test, mother's and father's education, 3 year averages of family size and household income as a child, and year dummy variables. Standard errors are reported in parentheses. The predicted effects, reported in brackets, give the share of a standard deviation in the dependent variable explained by a one standard deviation change in the sociability variables. The definitions of the variables are provided in the Data Appendix in Table A1 and A2. All estimates based on 44,036 person-year observations. 
Table 3

The Relationship Between Sociability at Age 16 and the Importance of Job Tasks in a Person's Occupation at Age 30 in Britain (Dependent Variables: Importance of Job Tasks)

\begin{tabular}{|c|c|c|c|c|c|c|}
\hline \multirow{3}{*}{$\begin{array}{l}\text { Importance of Job } \\
\text { Tasks in Current Job }\end{array}$} & \multirow{3}{*}{$\begin{array}{c}\text { St.Dev. of Dep. } \\
\text { Variable } \\
\text { (1) }\end{array}$} & \multicolumn{5}{|c|}{ Behavioral Indicators at Age 16} \\
\hline & & $\begin{array}{c}\text { Social Behavior } \\
\text { During School Term }\end{array}$ & $\begin{array}{l}\text { Social Behavior } \\
\text { During Holidays }\end{array}$ & $\begin{array}{c}\text { Social Behavior } \\
\text { During Leisure } \\
\text { Time }\end{array}$ & $\begin{array}{l}\text { Log of the Number } \\
\text { of Friends }\end{array}$ & $\begin{array}{l}\text { Self Description of } \\
\text { Character: Outgoing }\end{array}$ \\
\hline & & $(2)$ & (3) & $(4)$ & $(5)$ & $(6)$ \\
\hline People Tasks & 0.492 & $\begin{array}{c}0.005(0.001) \\
{[0.047]}\end{array}$ & $\begin{array}{c}0.005(0.001) \\
{[0.003]}\end{array}$ & $\begin{array}{c}0.006(0.002) \\
{[0.043]}\end{array}$ & $\begin{array}{c}0.021(0.012) \\
{[0.002]}\end{array}$ & $\begin{array}{c}0.017(0.004) \\
{[0.422]}\end{array}$ \\
\hline Math & 0.596 & $\begin{array}{c}-0.000(0.002) \\
{[0.001]}\end{array}$ & $\begin{array}{c}0.001(0.002) \\
{[0.001]}\end{array}$ & $\begin{array}{c}-0.005(0.002) \\
{[0.030]}\end{array}$ & $\begin{array}{c}-0.016(0.018) \\
{[0.001]}\end{array}$ & $\begin{array}{c}0.001(0.005) \\
{[0.021]}\end{array}$ \\
\hline Reading & 0.484 & $\begin{array}{c}-0.001(0.001) \\
{[0.010]}\end{array}$ & $\begin{array}{c}0.001(0.001) \\
{[0.001]}\end{array}$ & $\begin{array}{c}0.001(0.001) \\
{[0.007]}\end{array}$ & $\begin{array}{c}-0.014(0.011) \\
{[0.001]}\end{array}$ & $\begin{array}{c}0.002(0.003) \\
{[0.025]}\end{array}$ \\
\hline Writing & 0.590 & $\begin{array}{c}0.001(0.001) \\
{[0.008]}\end{array}$ & $\begin{array}{c}0.002(0.001) \\
{[0.001]}\end{array}$ & $\begin{array}{c}0.003(0.002) \\
{[0.018]}\end{array}$ & $\begin{array}{c}-0.006(0.013) \\
{[0.001]}\end{array}$ & $\begin{array}{c}0.006(0.004) \\
{[0.042]}\end{array}$ \\
\hline $\begin{array}{l}\text { Physical Strength } \\
\text { and Stamina }\end{array}$ & 0.833 & $\begin{array}{c}0.002(0.002) \\
{[0.011]}\end{array}$ & $\begin{array}{c}-0.001(0.002) \\
{[0.001]}\end{array}$ & $\begin{array}{c}0.004(0.003) \\
{[0.017]}\end{array}$ & $\begin{array}{c}0.052(0.021) \\
{[0.006]}\end{array}$ & $\begin{array}{c}-0.001(0.006) \\
{[0.088]}\end{array}$ \\
\hline Problem Solving & 0.502 & $\begin{array}{c}-0.001(0.001) \\
{[0.009]}\end{array}$ & $\begin{array}{c}0.001(0.001) \\
{[0.001]}\end{array}$ & $\begin{array}{c}0.000(0.002) \\
{[0.000]}\end{array}$ & $\begin{array}{c}0.005(0.012) \\
{[0.000]}\end{array}$ & $\begin{array}{c}-0.003(0.003) \\
{[0.024]}\end{array}$ \\
\hline Noticing Mistakes & 0.311 & $\begin{array}{c}-0.001(0.001) \\
{[0.015]}\end{array}$ & $\begin{array}{c}-0.000(0.001) \\
{[0.000]}\end{array}$ & $\begin{array}{c}-0.001(0.001) \\
{[0.011]}\end{array}$ & $\begin{array}{c}-0.007(0.008) \\
{[0.000]}\end{array}$ & $\begin{array}{c}-0.003(0.002) \\
{[0.118]}\end{array}$ \\
\hline $\begin{array}{l}\text { Planning of } \\
\text { Activities }\end{array}$ & 0.484 & $\begin{array}{c}0.003(0.001) \\
{[0.029]}\end{array}$ & $\begin{array}{c}0.005(0.001) \\
{[0.003]}\end{array}$ & $\begin{array}{c}0.005(0.002) \\
{[0.036]}\end{array}$ & $\begin{array}{c}0.024(0.012) \\
{[0.002]}\end{array}$ & $\begin{array}{c}0.011(0.003) \\
{[0.076]}\end{array}$ \\
\hline $\begin{array}{l}\text { Knowledge of the } \\
\text { Organization }\end{array}$ & 0.412 & $\begin{array}{c}-0.000(0.001) \\
{[0.001]}\end{array}$ & $\begin{array}{c}0.001(0.001) \\
{[0.000]}\end{array}$ & $\begin{array}{c}-0.001(0.001) \\
{[0.009]}\end{array}$ & $\begin{array}{c}-0.025(0.010) \\
{[0.002]}\end{array}$ & $\begin{array}{c}-0.001(0.003) \\
{[0.327]}\end{array}$ \\
\hline$n$ & & 3,749 & 3,464 & 3,267 & 3,915 & 3,566 \\
\hline
\end{tabular}

Note: All data taken from the British Cohort Study, except for the task measures in the current occupation. These are occupational averages from the British Skills Survey 2001 merged into the British Cohort Study. All regressions estimated using OLS and include controls for gender, marital status, and level of education. The predicted effects, in square brackets, give the share of a standard deviation in the dependent variable explained by a one standard deviation change in the sociability variables. The definitions of the variables are provided in the Data Appendix in Table A1 and A2. 
Table 4

Trends in the Relationship between Sociability and Log Wages in the United States (Dependent Variable: Log Wages)

\begin{tabular}{|c|c|c|c|c|c|c|c|c|c|}
\hline & \multicolumn{3}{|c|}{ Number of Clubs } & \multicolumn{3}{|c|}{ Sociability at Age 6} & \multicolumn{3}{|c|}{ Adult Sociability } \\
\hline \multicolumn{10}{|c|}{ Interactions with Time } \\
\hline Time*Sociability & 0.0023 & $(0.0007)$ & $* * *$ & -0.0001 & $(0.0009)$ & & 0.0009 & $(0.0012)$ & *** \\
\hline Time(After 1992)*Sociability & -0.0040 & $(0.0012)$ & $* * *$ & 0.0003 & $(0.0015)$ & & -0.0013 & $(0.0020)$ & $* * *$ \\
\hline \multicolumn{10}{|c|}{ Interactions with Time (Models that also Control for Interactions with Experience) } \\
\hline Time*Sociability & 0.0114 & $(0.0025)$ & $* * *$ & -0.0044 & $(0.0035)$ & & 0.0037 & $(0.0048)$ & $* * *$ \\
\hline Time(After 1992$) *$ Sociability & -0.0051 & $(0.0014)$ & $* * *$ & -0.0052 & $(0.0018)$ & $* * *$ & -0.0069 & $(0.0022)$ & $* * *$ \\
\hline
\end{tabular}

Note: All regressions contain 38,237 observations. All data taken from the NLSY79, except for the task measures in the current occupation. These are occupational averages merged in by occupation from the 1977 Dictionary of Occupational Titles. All regressions are estimated by including individual dummy variables, year dummy variables, education, a quadratic in experience and occupation random effects. Standard errors are reported in parentheses. The definitions of the variables are provided in the Data Appendix in Table A1 and A2. 
Table 5

The Effects of Job Tasks on Employment by Gender and Race in the United States, 1980-1990

\begin{tabular}{|c|c|c|c|c|c|c|}
\hline \multirow{2}{*}{1980 Cross-Sect } & \multicolumn{3}{|c|}{ Non-Blacks } & \multicolumn{3}{|c|}{ Blacks } \\
\hline & & & & & & \\
\hline \multicolumn{7}{|c|}{ Women } \\
\hline People Tasks & 0.030 & $(0.006)$ & {$[0.068]$} & 0.000 & $(0.001)$ & {$[0.000]$} \\
\hline Reasoning & 0.019 & $(0.058)$ & {$[0.017]$} & 0.018 & $(0.012)$ & {$[0.015]$} \\
\hline Mathematics & -0.033 & $(0.027)$ & {$[-0.030]$} & -0.022 & $(0.006)$ & {$[-0.020]$} \\
\hline Language & 0.230 & $(0.037)$ & {$[0.244]$} & 0.029 & $(0.008)$ & {$[0.031]$} \\
\hline Strength & -0.019 & $(0.022)$ & {$[-0.013]$} & 0.002 & $(0.005)$ & {$[0.001]$} \\
\hline Physical Tasks & -0.371 & $(0.053)$ & {$[-0.112]$} & -0.006 & $(0.011)$ & {$[-0.002]$} \\
\hline Specific Skills & -0.083 & $(0.016)$ & {$[-0.133]$} & -0.017 & $(0.003)$ & {$[-0.028]$} \\
\hline \multicolumn{7}{|c|}{ Men } \\
\hline People Tasks & -0.026 & $(0.007)$ & {$[-0.059]$} & -0.004 & 0.001 & {$[-0.010]$} \\
\hline Reasoning & -0.029 & $(0.062)$ & {$[-0.025]$} & -0.008 & 0.007 & {$[-0.007]$} \\
\hline Mathematics & 0.067 & $(0.029)$ & {$[0.062]$} & -0.012 & 0.003 & {$[-0.011]$} \\
\hline Language & -0.245 & $(0.039)$ & {$[-0.260]$} & -0.014 & 0.005 & {$[-0.015]$} \\
\hline Strength & 0.008 & $(0.023)$ & {$[0.006]$} & 0.009 & 0.003 & {$[0.006]$} \\
\hline Physical Tasks & 0.356 & $(0.056)$ & {$[0.108]$} & 0.022 & 0.007 & {$[0.007]$} \\
\hline Specific Skills & 0.100 & $(0.017)$ & {$[0.161]$} & 0.000 & 0.002 & {$[0.000]$} \\
\hline \multicolumn{7}{|c|}{ 1980-1990 Changes } \\
\hline \multicolumn{7}{|c|}{ Women } \\
\hline People Tasks & 0.021 & $(0.009)$ & [0.049] & -0.007 & $(0.003)$ & {$[-0.016]$} \\
\hline Reasoning & 0.019 & $(0.023)$ & {$[0.017]$} & 0.002 & $(0.007)$ & {$[0.002]$} \\
\hline Mathematics & -0.011 & $(0.013)$ & {$[-0.010]$} & -0.005 & $(0.004)$ & {$[-0.004]$} \\
\hline Language & 0.055 & $(0.014)$ & {$[0.058]$} & 0.013 & $(0.004)$ & {$[0.014]$} \\
\hline \multicolumn{7}{|c|}{ Men } \\
\hline People Tasks & -0.012 & $(0.009)$ & {$[-0.027]$} & -0.003 & $(0.002)$ & {$[-0.006]$} \\
\hline Reasoning & -0.008 & $(0.022)$ & {$[-0.007]$} & -0.014 & $(0.005)$ & {$[-0.012]$} \\
\hline Mathematics & 0.013 & $(0.013)$ & {$[0.012]$} & 0.003 & $(0.003)$ & {$[0.003]$} \\
\hline Language & -0.070 & $(0.013)$ & {$[-0.074]$} & 0.002 & $(0.003)$ & {$[0.002]$} \\
\hline
\end{tabular}


Table 6

The Effects of Job Tasks on Employment by Gender, Ethnicity, and Race in the United States, 1980-1990

\begin{tabular}{|c|c|c|c|c|c|c|}
\hline & \multicolumn{3}{|c|}{ Hispanics } & \multicolumn{3}{|c|}{ Other Race } \\
\hline \multicolumn{7}{|c|}{1980 Cross-Section } \\
\hline \multicolumn{7}{|c|}{ Women } \\
\hline People Tasks & 0.000 & $(0.001)$ & {$[0.000]$} & -0.001 & $(0.000)$ & {$[-0.002]$} \\
\hline Reasoning & -0.003 & $(0.005)$ & {$[-0.003]$} & 0.000 & $(0.004)$ & {$[0.000]$} \\
\hline Mathematics & -0.005 & $(0.002)$ & {$[-0.005]$} & -0.003 & $(0.002)$ & {$[-0.003]$} \\
\hline Language & 0.010 & $(0.003)$ & {$[0.011]$} & 0.010 & $(0.003)$ & {$[0.010]$} \\
\hline Strength & -0.005 & $(0.002)$ & {$[-0.004]$} & 0.000 & $(0.002)$ & {$[0.000]$} \\
\hline Physical Tasks & -0.016 & $(0.004)$ & {$[-0.005]$} & -0.021 & $(0.004)$ & {$[-0.006]$} \\
\hline Specific Skills & -0.005 & $(0.001)$ & {$[-0.008]$} & -0.005 & $(0.001)$ & {$[-0.008]$} \\
\hline \multicolumn{7}{|c|}{ Men } \\
\hline People Tasks & -0.002 & $(0.001)$ & {$[-0.005]$} & -0.003 & $(0.000)$ & {$[-0.007]$} \\
\hline Reasoning & -0.014 & $(0.005)$ & {$[-0.012]$} & -0.012 & $(0.004)$ & {$[-0.010]$} \\
\hline Mathematics & -0.002 & $(0.002)$ & {$[-0.002]$} & 0.003 & $(0.002)$ & {$[0.003]$} \\
\hline Language & -0.007 & $(0.003)$ & {$[-0.007]$} & -0.004 & $(0.003)$ & {$[-0.005]$} \\
\hline Strength & 0.007 & $(0.002)$ & {$[0.005]$} & 0.008 & $(0.001)$ & {$[0.005]$} \\
\hline Physical Tasks & 0.013 & $(0.005)$ & {$[0.004]$} & 0.000 & $(0.004)$ & {$[0.000]$} \\
\hline Specific Skills & 0.006 & $(0.001)$ & {$[0.010]$} & 0.003 & $(0.001)$ & {$[0.005]$} \\
\hline \multicolumn{7}{|c|}{ 1980-1990 Changes } \\
\hline \multicolumn{7}{|c|}{ Women } \\
\hline People Tasks & 0.002 & $(0.003)$ & {$[0.006]$} & 0.001 & $(0.002)$ & {$[0.001]$} \\
\hline Reasoning & -0.022 & $(0.007)$ & {$[-0.019]$} & 0.003 & $(0.004)$ & {$[0.002]$} \\
\hline Mathematics & 0.002 & $(0.004)$ & {$[0.002]$} & -0.002 & $(0.002)$ & {$[-0.002]$} \\
\hline Language & 0.014 & $(0.004)$ & {$[0.015]$} & -0.004 & $(0.002)$ & {$[-0.004]$} \\
\hline \multicolumn{7}{|c|}{ Men } \\
\hline People Tasks & 0.003 & $(0.004)$ & {$[0.008]$} & -0.002 & $(0.002)$ & {$[-0.005]$} \\
\hline Reasoning & -0.005 & $(0.009)$ & {$[-0.005]$} & -0.012 & $(0.004)$ & {$[-0.011]$} \\
\hline Mathematics & -0.009 & $(0.005)$ & {$[-0.008]$} & 0.003 & $(0.003)$ & {$[0.003]$} \\
\hline Language & 0.002 & $(0.006)$ & {$[0.003]$} & 0.001 & $(0.003)$ & {$[0.001]$} \\
\hline
\end{tabular}

Note: Dependent variable in the top (bottom) panel is (the change in) the employment share of the given group in an occupation. Regressions contain 496 occupations as the units of observation. Standard errors are reported in parentheses. Predicted effects of a one standard deviation change in the variable in brackets. Observations weighted by the size of occupations in 1980 (top panel) or the mean number of observations in 1980 and 1990 (bottom panel). 
Table 7

The Effects of Job Tasks on Employment of Workers by English Ability and Immigrant Status in the United States, 1980

\begin{tabular}{|c|c|c|c|c|c|c|c|c|c|}
\hline \multirow{3}{*}{ People Tasks } & \multicolumn{9}{|c|}{ English Best Category Given Speaks } \\
\hline & \multicolumn{3}{|c|}{ Speaks English at Home } & \multicolumn{3}{|c|}{ Other Language at Home } & \multicolumn{3}{|c|}{ Foreign Born } \\
\hline & 0.005 & $(0.001)$ & {$[0.012]$} & 0.017 & $(0.002)$ & {$[0.039]$} & -0.005 & $(0.001)$ & {$[-0.010]$} \\
\hline Reasoning & 0.022 & $(0.010)$ & {$[0.019]$} & 0.040 & $(0.022)$ & {$[0.035]$} & -0.017 & $(0.010)$ & {$[-0.015]$} \\
\hline Mathematics & 0.002 & $(0.004)$ & {$[0.002]$} & 0.013 & $(0.010)$ & {$[0.012]$} & 0.005 & $(0.004)$ & {$[0.005]$} \\
\hline Language & -0.003 & $(0.006)$ & {$[-0.003]$} & 0.028 & $(0.014)$ & {$[0.030]$} & -0.002 & $(0.006)$ & {$[-0.002]$} \\
\hline Strength & -0.014 & $(0.004)$ & {$[-0.010]$} & -0.044 & $(0.008)$ & {$[-0.031]$} & 0.012 & $(0.004)$ & [0.009] \\
\hline Physical Tasks & 0.046 & $(0.009)$ & {$[0.014]$} & 0.053 & $(0.020)$ & [0.016] & -0.051 & (0.009) & {$[-0.016]$} \\
\hline Specific Skills & -0.002 & $(0.003)$ & {$[-0.004]$} & -0.013 & $(0.006)$ & {$[-0.021]$} & 0.003 & $(0.003)$ & [0.004] \\
\hline
\end{tabular}

Note: Dependent variable is the employment share of the given group in an occupation. Estimates from seemingly unrelated regressions with 487 occupations as the units of observation. Standard errors are reported in parentheses. Predicted effects of a one standard deviation change in the variable in brackets. Observations weighted by the size of occupations in 1980. 
Table 8

Effect of Skills on Female Employment in Britain, 1997-2006

\begin{tabular}{|c|c|c|c|c|c|c|c|c|c|c|c|c|c|c|}
\hline \multirow[b]{4}{*}{ People Tasks } & \multicolumn{6}{|c|}{ A. Means and Standard Deviations } & \multicolumn{8}{|c|}{ B. Estimates } \\
\hline & \multirow{2}{*}{\multicolumn{2}{|c|}{$\begin{array}{l}1997 \\
(1) \\
\end{array}$}} & \multirow{2}{*}{\multicolumn{2}{|c|}{$\begin{array}{c}2001 \\
(2) \\
\end{array}$}} & \multirow{2}{*}{\multicolumn{2}{|c|}{$\begin{array}{c}2006 \\
(3) \\
\end{array}$}} & \multirow{2}{*}{\multicolumn{2}{|c|}{$\begin{array}{c}1997 \\
(4) \\
\end{array}$}} & \multirow{2}{*}{\multicolumn{2}{|c|}{$\begin{array}{c}2001 \\
(5) \\
\end{array}$}} & \multirow{2}{*}{\multicolumn{2}{|c|}{$\begin{array}{c}2006 \\
(6) \\
\end{array}$}} & \multirow{2}{*}{\multicolumn{2}{|c|}{$\frac{\text { Change 1997-2006 }}{(7)}$}} \\
\hline & & & & & & & & & & & & & & \\
\hline & 3.523 & $(0.662)$ & 3.593 & $(0.570)$ & 3.762 & $(0.509)$ & 0.251 & $(0.021)$ & 0.286 & $(0.017)$ & 0.261 & $(0.016)$ & 0.144 & $(0.011)$ \\
\hline Math & 2.627 & $(0.883)$ & 2.943 & $(0.639)$ & 2.712 & $(0.813)$ & -0.028 & $(0.013)$ & 0.015 & $(0.012)$ & 0.016 & $(0.010)$ & 0.049 & $(0.008)$ \\
\hline Reading & 3.634 & $(0.745)$ & 3.773 & $(0.588)$ & 3.736 & $(0.718)$ & 0.043 & $(0.028)$ & 0.176 & $(0.031)$ & -0.307 & $(0.037)$ & 0.002 & $(0.010)$ \\
\hline Writing & 3.304 & $(0.703)$ & 3.344 & $(0.635)$ & 3.229 & $(0.828)$ & 0.170 & $(0.024)$ & -0.001 & $(0.025)$ & 0.561 & $(0.034)$ & 0.011 & $(0.007)$ \\
\hline Physical Tasks & 2.588 & $(0.791)$ & 2.739 & $(0.791)$ & 2.761 & $(0.785)$ & -0.086 & $(0.011)$ & -0.066 & $(0.009)$ & -0.087 & $(0.008)$ & 0.062 & $(0.006)$ \\
\hline Problem Solving & 3.529 & $(0.763)$ & 3.557 & $(0.592)$ & 3.641 & $(0.598)$ & -0.139 & $(0.025)$ & -0.071 & $(0.022)$ & -0.286 & $(0.021)$ & -0.247 & $(0.013)$ \\
\hline Noticing Mistakes & 4.227 & $(0.522)$ & 4.259 & $(0.431)$ & 4.273 & $(0.369)$ & -0.067 & $(0.034)$ & -0.140 & $(0.032)$ & -0.028 & $(0.034)$ & 0.058 & $(0.015)$ \\
\hline Planning & 3.591 & $(0.732)$ & 3.689 & $(0.634)$ & 3.735 & $(0.599)$ & -0.229 & $(0.025)$ & -0.201 & $(0.022)$ & -0.274 & $(0.029)$ & -0.117 & $(0.010)$ \\
\hline Organzational Knowledge & 3.439 & $(0.648)$ & 3.595 & $(0.571)$ & 3.721 & $(0.482)$ & -0.059 & $(0.029)$ & -0.124 & $(0.025)$ & -0.149 & $(0.026)$ & 0.023 & $(0.011)$ \\
\hline $\mathrm{R}^{2}$ & & & & & & & 0.396 & & 0.379 & & 0.456 & & 0.102 & \\
\hline$n$ & 2,463 & & 4,470 & & 6,156 & & & & & & & & & \\
\hline Share of Women & 0.472 & $(0.355)$ & 0.479 & $(0.343)$ & 0.523 & $(0.326)$ & & & & & & & & \\
\hline
\end{tabular}

Note: Panel A reports means and standard deviations (in parentheses) of the importance of the various job task variables. Panel B columns (4)-(6) report effects of the importance of task variables on women's employment share in each occupation. Column (7) reports the effects of the change between 1997 and 2006 in all variables on the change in women's employment in each occupation. Observations in Panel B are three-digit occupations. Standard errors reported in parentheses. Regressions are estimated using 2SLS, with the importance of the job tasks instrumented by the importance of the job tasks among men. All regressions include controls for the education and experience mix of each occupation. 
Table 9

The Effects of Job Tasks on Female Employment in Germany, 1979-1998

\begin{tabular}{|c|c|c|c|c|c|c|c|c|c|c|c|c|c|}
\hline \multirow[b]{4}{*}{ People Tasks } & \multicolumn{4}{|c|}{ A. Means and Standard Deviations } & \multicolumn{9}{|c|}{ B. Regression Estimates } \\
\hline & \multirow{2}{*}{\multicolumn{2}{|c|}{$\frac{1979}{(1)}$}} & \multirow{2}{*}{\multicolumn{2}{|c|}{$\frac{1998}{(2)}$}} & \multirow{2}{*}{\multicolumn{3}{|c|}{$\frac{\text { GLS - Random Effects }}{(3)}$}} & \multirow{2}{*}{\multicolumn{3}{|c|}{$\frac{\text { Within - Fixed Effects }}{(4)}$}} & \multirow{2}{*}{\multicolumn{3}{|c|}{$\frac{\text { IV, Within - Fixed Effects }}{(5)}$}} \\
\hline & & & & & & & & & & & & & \\
\hline & 0.077 & $(0.058)$ & 0.465 & $(0.164)$ & 0.120 & $(0.016)$ & {$[0.047]$} & 0.103 & $(0.043)$ & {$[0.040]$} & 0.103 & $(0.051)$ & {$[0.040]$} \\
\hline Analytic Skills & 0.043 & $(0.057)$ & 0.160 & $(0.112)$ & -0.047 & $(0.016)$ & {$[-0.006]$} & 0.049 & $(0.044)$ & {$[0.006]$} & 0.049 & $(0.053)$ & {$[0.006]$} \\
\hline Routine Cognitive & 0.369 & $(0.253)$ & 0.209 & $(0.200)$ & -0.049 & $(0.005)$ & {$[0.008]$} & -0.052 & $(0.012)$ & {$[0.008]$} & -0.052 & $(0.013)$ & {$[0.008]$} \\
\hline Routine Manual & 0.331 & $(0.237)$ & 0.138 & $(0.199)$ & -0.008 & $(0.005)$ & {$[0.002]$} & -0.012 & $(0.012)$ & {$[0.002]$} & -0.012 & $(0.012)$ & {$[0.002]$} \\
\hline Non-Routine Manual & 0.156 & $(0.181)$ & 0.156 & $(0.221)$ & -0.032 & $(0.007)$ & {$[0.000]$} & 0.014 & $(0.021)$ & {$[0.000]$} & 0.014 & $(0.022)$ & {$[0.000]$} \\
\hline $\mathrm{R}^{2}$ & & & & & & & & .370 & & & .370 & & \\
\hline$n$ & 28,337 & & 25,739 & & 338 & & & 338 & & & & & 338 \\
\hline
\end{tabular}

Note: Panel A reports means and standard deviations (in parentheses) of the various skill variables. Panel B reports estimates of the relationship between the skill variables and women's employment share, with standard errors (in parentheses). The units of observation in Panel B are two-digit occupations, with each

occupation contributing an observation for each year. Numbers in brackets give the predicted effects of the change in the variable between 1979 and 1998 . The instrumental variables regressions are estimated by instrumenting for the importance of the job tasks by the importance of the job tasks among men. 


\section{Data Appendix}

\section{A.1. Constructing Job Task Measures Over Time}

Our main source of information on job tasks in the United States is the Fourth (1977) version of the Dictionary of Occupational Titles (DOT). Our procedures for working with these data follow those of Autor, Levy, and Murnane (2003). We merge information on job tasks from the DOT into the March CPS and 1980 and 1990 Censuses. Since the occupation classification in the DOT is much more detailed than the classification employed in the CPS and CPS, we use data from the April 1971 CPS (constructed by the Committee on Occupational Classification and Analysis of the National Academy of Science (1981)) in which all occupations are classified according to both the 1970 Census and the DOT classifications. We then calculate the mean of the DOT scores for each occupation in the Census Occupation Classification.

To bridge the periodic changes in the CPS/Census occupation classification, we used a common classification for the 1960s and 1970s developed by Autor, Levy and Murnane (2003) based on information from Priebe, Heinkel and Greene (1972). Differences between the occupational classifications used in the 1970s and the 1980s in the CPS are too large to develop a sensible crosswalk. For that reason we matched our data with the so-called Treiman file. This file contains 122,141 observations from the 1980 Census that are classified according to both the 1970 and 1980 Census / CPS classification systems. Using this file, we calculated scores for the 1980 occupations. Based on a crosswalk between the 1980s and 1990s CPS classifications developed by Autor, Katz and Krueger (1998) we put the CPS classification for both decades into one framework. Subsequently, we append the DOT information to the CPS.

To investigate changes in tasks within occupations between the Fourth version of the DOT from 1977 and the 1991 Fourth Revised Edition, we matched occupation characteristics from the Revised Edition of the DOT (U.S. Department of Labor (1994)), to occupations using the conversion tables of code and title changes from the Fourth to Revised Fourth Edition Dictionary of Occupational Titles. Table A1 lists the specific variables used to measure the importance of people tasks in the DOT and in the other datasets described below.

\section{A.2. Current Population Surveys}

To measure task importance, we use all observations for workers, aged 18-64. To measure supply we weighted all observations by hours worked times weeks worked. For the years in the CPS for which the number of weeks worked are not known, we assumed that part year workers worked half of the year. People who worked full-time were assumed to work 40 hours per week.

Employment rates have changed substantially, with white women working more and young black men, in particular, working less (in part due to incarceration). To control for changes in selection into the workforce when estimating wages we impute wages for people who do not work in a given year. To do this, we use 2-year panels from the Current Population Survey (generously provided by Donghoon Lee; see Lee and Wolpin (2006) for a description of the data). We break the labor market into 4 groups based on gender and race (black and non-black) and perform all imputations separately for each group. We begin by splitting the four groups by education (into 9 consistent categories) and by individual years of potential experience. Using data on the institutionalized population from the 1970, 1980, 1990, and 2000 Censuses, we linearly interpolate / extrapolate the share of workers in each gender-race-education-experience cell that are incarcerated.

For people who are either incarcerated in a given year (and therefore not in the CPS sampling frame) or are not employed in both years in which they appear in the CPS, we impute 
wages using the wages of people with the same characteristics who worked in only one year of the panel. To do this, for each of the four gender-race groups, we regress log wages on year dummy variables, education dummy variables, and a quartic in experience. The education and experience variables capture cross-sectional differences in wages, while the year dummy variables capture changes in the heights of the profiles. We use these regressions to predict wages for people who are incarcerated or not working in a given year based on the year and their gender, race, education, and experience. ${ }^{32}$

For people who only work in one year, we use a related procedure to impute their wage in the year in which they did not work. We start with their wage in the year in which they did work and adjust that wage for wage changes between the surveys for workers with the same observable characteristics. To do this, for each of the four gender-race groups, we regress log wage changes for people who work in both years on year dummy variables; education dummy variables; and a quartic in experience. We then predict wage changes between the surveys for people who only work in one of the survey years based on the year, their gender, race, education, and experience. ${ }^{33}$

\section{A.3. NLSY and Census}

We use data from the National Longitudinal Survey of Youth of 1979 (NLSY79) to estimate the effect of people skills on labor-market outcomes. In 1984, respondents to the NLSY79 were asked about the number of clubs they participated in during high school. The 1985 survey, conducted when the respondents were 20-28 years old, contains data on contemporaneous sociability and sociability at age 6 . Table A2 lists the specific variables we used to measure sociability in the NLSY79 and in the other datasets discussed below. We estimate the relationship between sociability and the tasks in adult occupations by assigning respondents the 1977 DOT scores associated with the three-digit occupation in which they are employed in each year. We also estimate the relationship between sociability and wages using the hourly rates of pay, which were converted to 1982-1984 dollars. Respondents with hourly rates of pay beneath $\$ 1$ per hour or above $\$ 100$ per hour were deleted from the sample. We exploit the panel aspects of the NLYS79 by using data for all years for which wages are reported. The NLSY79 is attractive because it contains a wealth of information about individuals, including parents' education, the respondents' score on the Armed Forces Qualifying Test, and characteristics of the household in which the respondent was raised.

We use the five percent Public Use Micro Samples of the 1980 and 1990 Census to estimate the share of workers in each three-digit occupation who are black; other race (American Indians, Asians, Pacific Islander's, etc.); from a Hispanic background; who speak a language other than English at home; whose English is very good (the highest category) conditional on speaking a language other than English at home; and who were born outside of the United States and its territories. The sample was restricted to people who held a job at the time of the survey between ages 18 and 65 and who were not enrolled in school. All observations with imputed values for any variable used in the analysis were deleted. In the 1990 Census, individuals were weighted using the person weight. These measures of the demographic composition of each occupation were then merged to measures of task importance from the 1977 DOT.

\footnotetext{
${ }^{32}$ Because the year dummy variables are noisy, we smooth those using local linear regressions with a bandwidth of 4 years.

${ }^{33}$ Again, we smooth the year dummy variables using local linear regressions with a bandwidth of 4 years.
} 


\section{A.4. BSS and BCS}

The First (1997), Second (2001), and Third (2006) British Skills Surveys (BSS) are representative cross-sectional samples of the employed British population between ages 20 and 60 . The ESRC Centre on Skills, Knowledge and Organisational Performance (SKOPE) initiated the first edition of the BSS in 1997 aimed at "investigating the skills used at work in Britain ... (and) to collect data from individual job-holders on a rich array of variables characterizing British jobs. The intention is that the survey generates a more valid and detailed picture of skills than is normally available from examining individuals' qualifications or their occupations" (Ashton et al. 1998, 5). The most innovative feature of these data is that they embed job analysis principles and procedures into a conventional representative survey. The second and third BSS are updates of the first and are similar in structure. The first survey contains 2,467 workers; the second includes 4,470 workers; and the third contains 6,156 observations. These surveys were conducted face-toface. The interviewers assess the importance of 36 job activities and key skills, from which we construct nine job tasks: problem solving, noticing mistakes, mathematical ability, reading and writing, physical skills, the ability to plan activities, knowledge about products and the workplace and people tasks (see e.g., Table A1).

The 1970 Birth Cohort Study (BCS) began as the British Birth Survey. It includes over 17,000 babies born in Britain in the week 5-11 April 1970. ${ }^{34}$ Major follow-ups were conducted in $1975,1980,1986$, and 1996 . We focus on the sociability questions asked in 1986 when the cohort members were 16 years old. The latest major survey was held in 2000 and contains data on respondents' labor-market status at age 30, including their occupations. We selected those cohort members that were in paid work and not self employed in 2000.

We aggregated occupations to the 3-digit level of the 1990 U.K. Standard Occupational Classification (SOC90), which identifies 371 occupations. ${ }^{35}$ We use all observations for non-self employed workers.

To analyze how sociability affects occupational choice, we assign each worker in the 2000 BCS the mean value of the nine job tasks among people in his three-digit occupation estimated from the 2001 BSS. We then estimated the relationship between sociability at age 16 and the tasks that are important on the respondents' jobs at age 30 . Table A2 presents the definitions and some descriptive statistics of our constructs of sociability.

\section{A.5. BIBB/IAB}

The data collected by the Bundesinstitut für Berufsbildung (BIBB) in Berlin and Institut für Arbeitsmarkt- und Berufsforschung der Bundesanstalt für Arbeit (IAB) in Nürnberg are representative surveys of the German workforce. This BIBB/IAB database contains four crosssectional surveys of the German workforce ages 16 to 65 and was conducted in 1979, 1985, 1991 and 1998. Each round has about 30,000 respondents. The surveys contain standard demographic and labor-market variables and rich information about employed respondents' jobs, job attributes, the tools used in these jobs, the skills necessary to perform a job, and how these skills were obtained. Our samples eliminate workers from the former East Germany (who were only included

\footnotetext{
${ }^{34}$ We use the BCS instead of the earlier NCDS because the NCDS does not contain measures of sociability.

${ }^{35}$ For Britain, samples of the Standard Occupational Classification 1990 (SOC90) are available. The SOC90 was published to replace both the Classification of Occupations 1980 (CO80) and the Classification of Occupations and Dictionary of Occupational Titles (CODOT). The SOC90 includes nine major groups divided into 22 sub-major groups of occupations. These 22 groups can be divided into 371 unit groups, which we define as occupations. These unit groups are the aggregate results of over 26,000 job titles.
} 
in the survey since 1991), the self-employed, and the unemployed. The questions are similar across the 3 surveys. We aggregated the data from all four years into 83 two-digit occupations, the finest level at which it was possible to construct a consistent occupational classification.

\section{A.6. Computerization}

Data on computer use at work in the United States is available on the School Enrollment Supplements to the 1984, 1989, 1993, 1997, and 2001 October CPS. Since our DOT variables reflect the period 1977-1991, we use the earliest (1984) survey and the 1993 survey. Individual computer use is calculated as the fraction of currently employed workers who answered yes to the question, "Do you use a computer directly at work?" The survey defines a computer as a desktop terminal or PC with keyboard and monitor and does not include an electronic cash register or a hand-held data-device. The samples contain 60,396 and 59,710 observations. Computer use increases from 26.1 percent in 1984 to 34.9 percent in 1993.

For Germany the computer questions change slightly between 1979 wave and the later waves. For the 1979 survey we combine answers to two questions. The first asked about the use of "computers, terminals, or monitors," and the second inquired about word processors. In the later surveys there are six categories - computers on shop floors, office computers, PCs, terminals, word processors, and CAD systems - which we combine into one dummy variable. Using this procedure, computer use in Germany increases from 5.6 percent in 1979 to 53.7 percent in 1998.

To compute computer use in Britain we use responses to "How important is using a computer or computerized equipment in your job?" in the two waves of the BSS. If the answer is essential, very important, important, or slightly important, computer use is equal to one. If the answer is not important at all/does not apply, computer use is equal to zero. Using this coding, computer use rises from 69.2 percent in 1997 to 78.1 percent in 2001 to 79.3 percent in 2006. When we use the more gradual scale instead of a dummy variable, the regression results remain similar in qualitative terms, although the significance drops somewhat. 
Table A1

Definitions of People Tasks in the United States, Germany, and Britain

\begin{tabular}{|c|c|c|c|c|c|}
\hline Country & Data Source & Definition of People Tasks & Variable Construction & \multicolumn{2}{|c|}{$\begin{array}{c}\text { Mean } \\
\text { (Standard Deviation) } \\
\text { (Year) }\end{array}$} \\
\hline $\begin{array}{l}\text { United } \\
\text { States }\end{array}$ & $\begin{array}{l}\text { Dictionary of Occupational } \\
\text { Titles Fourth (1977) and } \\
\text { Revised Fourth Edition (1991) }\end{array}$ & $\begin{array}{l}\text { We use three variables from the DOT } \\
\text { temperaments: (i) adaptability to situations } \\
\text { involving the interpretation of feelings, ideas or } \\
\text { facts in terms of personal viewpoint, (ii) } \\
\text { adaptability to influencing people in their } \\
\text { opinions, attitudes or judgments about ideas or } \\
\text { things, and (iii) adaptability to dealing with } \\
\text { people beyond giving and receiving instructions. } \\
\text { Two variables from DOT interest factors signify } \\
\text { interests, tastes and preferences for certain } \\
\text { people tasks: (i) a preference for activities } \\
\text { involving business contact with people, and (ii) a } \\
\text { preference for working for the presumed good of } \\
\text { people. }\end{array}$ & $\begin{array}{l}\text { The presence or absence of } \\
\text { a given temperament, rather } \\
\text { than the level or degree } \\
\text { required, is indicated. } \\
\text { Temperaments are coded } 0 \\
\text { or } 1 . \text { The interests equal }-1 \text {, } \\
0 \text {, or } 1 . \text { In constructing the } \\
\text { measures we normalize } \\
\text { these five items by their } \\
\text { standard deviations and use } \\
\text { their sum. }\end{array}$ & $\begin{array}{l}.9274 \\
\text { (DOT'77 in } \\
1977) \\
.9408 \\
\text { (DOT'91 in } \\
1977)\end{array}$ & $\begin{array}{l}1.1499 \\
\text { (DOT' } 77 \text { in } \\
1991 \text { ) } \\
1.1788 \\
\text { (DOT' '91 in } \\
1991 \text { ) }\end{array}$ \\
\hline Germany & $\begin{array}{l}\text { Bundesinstitut für } \\
\text { Berufsbildung (BIBB) and } \\
\text { Institut für Arbeitsmarkt- und } \\
\text { Berufsforschung der } \\
\text { Bundesanstalt für Arbeit } \\
\text { (IAB) }(1979,1985,1991 \text {, and } \\
\text { 1998) }\end{array}$ & $\begin{array}{l}\text { We use variables for whether the job involves } \\
\text { negotiating, lobbying, coordinating and } \\
\text { organizing; teaching or training; selling, buying, } \\
\text { advising, or advertising; entertaining or } \\
\text { presenting; serving and accommodating; and } \\
\text { helping others }\end{array}$ & $\begin{array}{l}\text { The variables are coded } 0 \\
\text { or } 1 . \text { We average across the } \\
\text { responses to the questions. }\end{array}$ & $\begin{array}{c}0.077 \\
(0.058) \\
(1979)\end{array}$ & $\begin{array}{c}0.465 \\
(0.164) \\
(1998)\end{array}$ \\
\hline Britain & $\begin{array}{l}\text { First (1997) and Second } \\
\text { (2001) and Third (2006) } \\
\text { British Skills Survey }\end{array}$ & $\begin{array}{l}\text { We use variables for the importance of dealing } \\
\text { with people; working with a team of people; } \\
\text { instructing, training or teaching people; making } \\
\text { speeches or presentations; persuading or } \\
\text { influencing others; selling a product; counseling, } \\
\text { advising or caring for customers or clients; and } \\
\text { listening carefully to colleagues }\end{array}$ & $\begin{array}{l}\text { The variables range from } 1 \\
\text { (not important) to } 5 \\
\text { (essential). We average } \\
\text { across the responses to the } \\
\text { various questions. }\end{array}$ & $\begin{array}{c}3.468 \\
(0.933) \\
(1997)\end{array}$ & $\begin{array}{c}3.554 \\
(0.875) \\
(2001)\end{array}$ \\
\hline
\end{tabular}




\section{Table A2}

Definitions of Sociability in the United States, and Britain

\begin{tabular}{|c|c|c|c|c|}
\hline \multirow{2}{*}{$\begin{array}{l}\text { Country } \\
\text { (Data) }\end{array}$} & \multicolumn{2}{|r|}{ Sociability Variables } & \multirow[t]{2}{*}{ Variable Construction } & \multirow{2}{*}{$\begin{array}{c}\text { Mean } \\
\text { (Standard Deviation) }\end{array}$} \\
\hline & Measure & Definition & & \\
\hline \multirow{3}{*}{$\begin{array}{l}\text { United } \\
\text { States } \\
(\text { NLSY79) }\end{array}$} & Clubs & $\begin{array}{l}\text { Respondents were shown cards with } 9 \text { types of high school clubs and } \\
\text { asked how many of them they participated in during high school. }\end{array}$ & $\begin{array}{l}\text { The sum of the number } \\
\text { of different types of } \\
\text { clubs is used. }\end{array}$ & $\begin{array}{c}1.970 \\
(1.183)\end{array}$ \\
\hline & $\begin{array}{l}\text { Sociability at } \\
\text { age } 6\end{array}$ & $\begin{array}{l}\text { Respondents were asked, "Thinking of yourself when you were } 6 \text { years } \\
\text { old, would you describe yourself as: (1) extremely shy; (2) somewhat shy; } \\
\text { (3) somewhat outgoing; or (4) extremely outgoing?" }\end{array}$ & $\begin{array}{l}\text { The responses are } \\
\text { used. }\end{array}$ & $\begin{array}{c}2.421 \\
(0.912)\end{array}$ \\
\hline & $\begin{array}{l}\text { Sociability in } \\
\text { adulthood }\end{array}$ & $\begin{array}{l}\text { Respondents were asked, "Thinking of yourself as an adult, would you } \\
\text { describe yourself as: (1) extremely shy; (2) somewhat shy; (3) somewhat } \\
\text { outgoing; or (4) extremely outgoing?" }\end{array}$ & $\begin{array}{l}\text { The responses are } \\
\text { used. }\end{array}$ & $\begin{array}{l}2.949 \\
(0.663)\end{array}$ \\
\hline \multirow{5}{*}{$\begin{array}{l}\text { Britain } \\
\text { (BCS) }\end{array}$} & $\begin{array}{l}\text { Social behavior } \\
\text { during school } \\
\text { term }\end{array}$ & $\begin{array}{l}\text { Measures include: Stay at home with boy/girlfriend; Stay at home of } \\
\text { boy/girlfriend; Go to the cinema etc. with boy/girlfriend; Stay at home } \\
\text { with other friends; Spend time at the homes of other friends; Go with } \\
\text { friends to cinema, disco etc.; and Go out with friends do nothing special }\end{array}$ & $\begin{array}{l}\text { Respondents are asked } \\
\text { if they are engaged in } \\
\text { the social activities } \\
\text { listed. The responses }\end{array}$ & $\begin{array}{l}8.764 \\
(4.657)\end{array}$ \\
\hline & $\begin{array}{l}\text { Social behavior } \\
\text { during holidays }\end{array}$ & $\begin{array}{l}\text { Measures include: Stay at home by yourself or with family; Go out by } \\
\text { myself or with family; Go to a friend's house; Have friends round to my } \\
\text { house; Go to a youth club/organization; Go out with brothers/sisters; Do } \\
\text { community/volunteer work; Go to a meeting/political club; Go out with } \\
\text { my boy/girlfriend; and Go out with friends }\end{array}$ & $\begin{array}{l}\text { range from } 0 \text { to } 5 \\
\text { measuring the } \\
\text { frequency of the } \\
\text { activity. We construct } \\
\text { dummy variables equal }\end{array}$ & $\begin{array}{l}10.574 \\
(5.361)\end{array}$ \\
\hline & $\begin{array}{l}\text { Social behavior } \\
\text { during leisure } \\
\text { time }\end{array}$ & $\begin{array}{l}\text { Measures include: Go to a friend's house; Have friends round to my } \\
\text { house; Go to a youth club/organization; Go out with brothers/sisters; Do } \\
\text { community/volunteer work; Go to a meeting/political club; Go out with } \\
\text { my boy/girlfriend; and Go out with friends }\end{array}$ & $\begin{array}{l}\text { to } 1 \text { if the response is } \\
1-5 . \text { For the number of } \\
\text { friends we use the } \\
\text { absolute number of }\end{array}$ & $\begin{array}{l}17.023 \\
(4.048)\end{array}$ \\
\hline & $\begin{array}{l}\text { Number of } \\
\text { friends }\end{array}$ & $\begin{array}{l}\text { Measures include: Number of Boy or Girl friends; Number of best } \\
\text { friends; Number of friends in school; and Number of friends outside } \\
\text { school }\end{array}$ & $\begin{array}{l}\text { friends, including } \\
\text { whether the person has } \\
\text { a boy/girlfriend. For }\end{array}$ & $\begin{array}{l}11.780 \\
(5.482)\end{array}$ \\
\hline & $\begin{array}{l}\text { Self description } \\
\text { of character: } \\
\text { outgoing }\end{array}$ & $\begin{array}{l}\text { Respondents are asked, "I am ..." Friendly; Loving; Outgoing; Shy } \\
\text { (entered in reverse); and Quiet (entered in reverse). The response } \\
\text { categories are (1) does not apply; (2) applies somewhat; (3) applies very } \\
\text { much. We average the responses. }\end{array}$ & $\begin{array}{l}\text { the self description, we } \\
\text { average across the } \\
\text { variables? }\end{array}$ & $\begin{array}{c}2.542 \\
(1.816)\end{array}$ \\
\hline
\end{tabular}

Note: The data source for the United States is the NLSY79 and for Britain the BCS. 
Table A3

The 25 Largest Occupations in the 1980 United States Census Ranked by the Importance of People Tasks

\begin{tabular}{|c|c|c|c|c|c|c|c|}
\hline People Tasks & Reasoning & Math & Language & Strength & Physical & $\begin{array}{c}\text { Specific } \\
\text { Vocational } \\
\text { Training }\end{array}$ & Occupation \\
\hline 4.842 & 3.920 & 2.986 & 3.833 & 1.829 & 0.011 & 5.056 & Sales representatives mining manufacturing and wholesale \\
\hline 4.375 & 3.553 & 2.927 & 3.137 & 1.944 & 0.057 & 3.804 & Sales workers other commodities \\
\hline 3.880 & 4.985 & 3.045 & 4.962 & 1.944 & 0.009 & 6.130 & Teachers elementary school \\
\hline 3.602 & 2.918 & 1.993 & 2.237 & 2.004 & 0.016 & 3.011 & Waiters and waitresses \\
\hline 3.570 & 3.997 & 2.925 & 3.976 & 1.007 & 0.003 & 6.001 & Secretaries \\
\hline 3.525 & 3.259 & 2.262 & 2.574 & 3.025 & 0.764 & 4.251 & Nursing aides orderlies and attendants \\
\hline 2.929 & 4.343 & 3.734 & 3.753 & 1.347 & 0.060 & 6.999 & Supervisors and proprietors sales occupations \\
\hline 2.884 & 4.330 & 3.769 & 3.818 & 1.367 & 0.049 & 7.011 & Managers and administrators n.e.c. \\
\hline 2.654 & 3.137 & 2.470 & 2.178 & 2.000 & 0.009 & 3.003 & Cashiers \\
\hline 2.225 & 3.682 & 2.728 & 3.419 & 1.304 & 0.019 & 4.643 & General office clerks \\
\hline 1.955 & 4.919 & 3.922 & 4.904 & 2.814 & 0.025 & 6.881 & Registered nurses \\
\hline 0.960 & 4.067 & 3.138 & 3.282 & 1.641 & 0.131 & 6.905 & Supervisors production occupations \\
\hline 0.167 & 2.293 & 1.860 & 1.745 & 2.869 & 0.362 & 2.637 & Laborers except construction \\
\hline 0.167 & 2.293 & 1.860 & 1.745 & 2.869 & 0.362 & 2.637 & Stock handlers and baggers \\
\hline-0.395 & 2.956 & 1.809 & 2.126 & 1.900 & 0.516 & 3.455 & Truck drivers light \\
\hline-0.395 & 2.956 & 1.809 & 2.126 & 1.900 & 0.516 & 3.455 & Truck drivers heavy \\
\hline-0.578 & 2.418 & 1.795 & 2.173 & 3.143 & 0.870 & 3.452 & Janitors and cleaners \\
\hline-0.925 & 2.554 & 1.590 & 1.904 & 1.997 & 0.171 & 3.318 & Assemblers \\
\hline-0.925 & 4.000 & 3.703 & 3.073 & 1.018 & 0.005 & 4.834 & Bookkeeping accounting and auditing clerks \\
\hline-1.117 & 3.484 & 2.527 & 2.651 & 2.909 & 0.146 & 5.929 & Short-order cooks \\
\hline-1.296 & 3.265 & 2.368 & 2.387 & 2.088 & 0.475 & 5.454 & Machine operators n.s. \\
\hline-1.577 & 3.887 & 2.915 & 2.956 & 2.870 & 0.883 & 6.750 & Automobile mechanics except apprentices \\
\hline-1.661 & 3.924 & 3.010 & 2.880 & 2.956 & 0.932 & 6.849 & Carpenters except apprentices \\
\hline-1.953 & 4.806 & 4.611 & 4.642 & 0.969 & 0.002 & 7.268 & Accountants and auditors \\
\hline-2.597 & 3.844 & 3.654 & 3.684 & 3.242 & 0.803 & 6.625 & Farmers except horticultural \\
\hline
\end{tabular}




\section{Table A4}

The 10 Largest Occupations in 1979 and 1991 in the German BIBB/IAB Ranked by the Importance of People Tasks

\begin{tabular}{|c|c|c|c|c|c|c|}
\hline \multicolumn{7}{|c|}{10 Largest Occupations in 1979} \\
\hline \multicolumn{4}{|c|}{ Ranked According to the Importance of People Tasks in 1979} & \multicolumn{3}{|c|}{ Ranked According to the Importance of People Tasks in 1991} \\
\hline 1979 & 1991 & \%Change & Occupation & 19791991 & \%Change & Occupation \\
\hline 0.290 & 0.310 & 0.069 & Registered Nurses and care takers & 0.2900 .310 & 0.069 & Registered Nurses and care takers \\
\hline 0.220 & 0.260 & 0.182 & Teachers & 0.1900 .260 & 0.368 & Organizers and entrepreneurial occupations \\
\hline 0.190 & 0.260 & 0.368 & Organizers and entrepreneurial occupations & 0.2200 .260 & 0.182 & Teachers \\
\hline 0.160 & 0.210 & 0.313 & Sales persons (goods) & $0.140 \quad 0.250$ & 0.786 & Health occupations \\
\hline 0.140 & 0.250 & 0.786 & Health occupations & 0.1200 .210 & 0.750 & Secretaries \\
\hline 0.130 & 0.160 & 0.231 & Engineers (chemical, physics, and math) & 0.1600 .210 & 0.313 & Sales persons (goods) \\
\hline 0.120 & 0.210 & 0.750 & Secretaries & 0.0900 .190 & 1.111 & Sales persons (bank services and insurance) \\
\hline 0.100 & 0.120 & 0.200 & Engineers (technical) & 0.0900 .170 & 0.889 & Security persons \\
\hline 0.090 & 0.190 & 1.111 & Sales persons (bank services and insurance) & 0.1300 .160 & 0.231 & Engineers (chemical, physics, and math) \\
\hline 0.090 & 0.170 & 0.889 & Security persons & 0.1000 .120 & 0.200 & Engineers (technical) \\
\hline \multicolumn{7}{|c|}{10 Largest Occupations in 1991} \\
\hline \multicolumn{4}{|c|}{ Ranked According to the Importance of People Tasks in 1979} & \multicolumn{3}{|c|}{ Ranked According to the Importance of People Tasks in 1991} \\
\hline 0.220 & 0.260 & 0.182 & Teachers & 0.2200 .260 & 0.182 & Teachers \\
\hline 0.160 & 0.210 & 0.313 & Sales persons (goods) & 0.1400 .250 & 0.786 & Registered Nurses and care takers \\
\hline 0.140 & 0.250 & 0.786 & Registered Nurses and care takers & 0.1600 .210 & 0.313 & Sales persons (goods) \\
\hline 0.130 & 0.160 & 0.231 & Engineers (chemical, physics, and math) & 0.1300 .160 & 0.231 & Engineers (chemical, physics, and math) \\
\hline 0.100 & 0.120 & 0.200 & Engineers (technical) & 0.1000 .120 & 0.200 & Engineers (technical) \\
\hline 0.060 & 0.100 & 0.667 & Secretaries & 0.0600 .100 & 0.667 & Secretaries \\
\hline 0.050 & 0.060 & 0.200 & Laborers except construction & 0.0400 .100 & 1.500 & Cash operators and book keepers \\
\hline 0.040 & 0.100 & 1.500 & Cash operators and book keepers & 0.0500 .060 & 0.200 & Laborers except construction \\
\hline 0.020 & 0.040 & 1.000 & Truck drivers & 0.0200 .040 & 1.000 & Truck drivers \\
\hline 0.020 & 0.020 & 0.000 & Machine operators n.s. & 0.0200 .020 & 0.000 & Machine operators n.s. \\
\hline
\end{tabular}


Table A5

The 10 Occupations with Largest Increases and Decreases in People Tasks in Germany between 1979 and 1991

\begin{tabular}{clcl}
\hline \% Change & \multicolumn{1}{c}{ 10 Occupations with largest increase in people tasks } & \% Change & \multicolumn{1}{c}{ 10 Occupations with largest decrease in people tasks } \\
\hline 0.667 & Secretaries & -0.116 & House Painters \\
0.786 & Registered Nurses and care takers & -0.164 & Glassblowers \\
0.889 & Security persons & -0.248 & Bricklayers \\
0.892 & Doctors & -0.254 & Moving men \\
1.000 & Truck Drivers & -0.257 & Technicians \\
1.111 & Sales persons (bank services and insurance) & -0.414 & Cleaners \\
1.258 & Hair dressers & -0.535 & Potters \\
1.357 & Musicians & -0.561 & Paper constructors \\
1.500 & Cash operators and book keepers & -0.625 & Rollers \\
1.940 & Entrepreneurs & -0.899 & Tailors \\
\hline
\end{tabular}


Publisher:

CPB Netherlands Bureau for Economic Policy Analysis

P.O. Box $80510 \mid 2508$ GM The Hague

$\mathrm{T}(070) 3383380$

September 2013 | ISBN 978-90-5833-612-5 